\title{
Application of Machine Learning to Bending Processes and Material Identification
}

\author{
Daniel J. Cruz ${ }^{1, *(\mathbb{D}}$, Manuel R. Barbosa ${ }^{2} \mathbb{D}$, Abel D. Santos ${ }^{2}$, Sara S. Miranda ${ }^{1}$ and Rui L. Amaral ${ }^{1}$ \\ 1 INEGI, Institute of Science and Innovation in Mechanical and Industrial Engineering, R. Dr. Roberto Frias 400, \\ 4200-465 Porto, Portugal; smiranda@inegi.up.pt (S.S.M.); ramaral@inegi.up.pt (R.L.A.) \\ 2 FEUP, Faculty of Engineering, University of Porto, R. Dr. Roberto Frias, 4200-465 Porto, Portugal; \\ mbarbosa@fe.up.pt (M.R.B.); abel@fe.up.pt (A.D.S.) \\ * Correspondence: dcruz@inegi.up.pt
}

Citation: Cruz, D.J.; Barbosa, M.R.; Santos, A.D.; Miranda, S.S.; Amaral, R.L. Application of Machine Learning to Bending Processes and Material Identification. Metals 2021, 11, 1418. https://doi.org/10.3390/met11091418

Academic Editor: Lijun Zhang

Received: 30 July 2021

Accepted: 3 September 2021

Published: 7 September 2021

Publisher's Note: MDPI stays neutral with regard to jurisdictional claims in published maps and institutional affiliations.

Copyright: (c) 2021 by the authors. Licensee MDPI, Basel, Switzerland. This article is an open access article distributed under the terms and conditions of the Creative Commons Attribution (CC BY) license (https:// creativecommons.org/licenses/by/ $4.0 /)$.

\begin{abstract}
The increasing availability of data, which becomes a continually increasing trend in multiple fields of application, has given machine learning approaches a renewed interest in recent years. Accordingly, manufacturing processes and sheet metal forming follow such directions, having in mind the efficiency and control of the many parameters involved, in processing and material characterization. In this article, two applications are considered to explore the capability of machine learning modeling through shallow artificial neural networks (ANN). One consists of developing an ANN to identify the constitutive model parameters of a material using the force-displacement curves obtained with a standard bending test. The second one concentrates on the springback problem in sheet metal press-brake air bending, with the objective of predicting the punch displacement required to attain a desired bending angle, including additional information of the springback angle. The required data for designing the ANN solutions are collected from numerical simulation using finite element methodology (FEM), which in turn was validated by experiments.
\end{abstract}

Keywords: artificial neural networks (ANN); machine learning (ML); press-brake bending; air-bending; three-point bending test; sheet metal forming

\section{Introduction}

Sheet metal forming has been employed for centuries in diverse manufacturing industries to create a wide range of products that may be used in several applications. Among different forming techniques, sheet bending and stamping can be considered the most important variants in forming industry. These techniques have been continuously improved in recent decades to meet the growing need for lightweight metallic components in the automotive sector in order to address environmental concerns about energy efficiency and emissions [1,2]. To bend a sheet metal material, different methods can be used such as air bending, coining, and bottom bending. Air bending, Figure 1a, is a process in which the punch deforms the sheet by bending without the sheet being coined against the bottom die. Therefore, it is frequently the preferred bending method because it provides a high level of flexibility, as it is possible to obtain different bending angles using the same set of tools by only controlling the punch stroke. However, this process is characterized by strong nonlinear behavior, considering its parameters and their interrelationships [3].

In bending operations, one of the most important issues to consider is the springback effect. In fact, the removal of the tools causes the release of the installed residual stresses, leading to elastic recovery of the material and a change in the final bending angle. Consequently, estimating the springback effect becomes a vital requirement for achieving an accurate and regulated procedure. To address this issue, several authors tried to estimate the springback behavior in bending operations in order to develop compensation methods based on experimental, analytic and numerical approaches. The authors of [4-8] proposed analytic solutions to reproduce the evolution of the bending angle with the 
punch displacement for a certain combination of sheet material and tools. However, these analytical approaches are often established upon simplifications and assumptions based on the material properties and tool geometry, which sometimes lead to inconsistent results [9]. To overcome these limitations, finite element analysis (FEA) is widely used as a process modeling tool always supported by experimental validation [10,11]. In this context, [12] studied the springback effect of different types of high-strength steels using FEA models. The authors of [13] developed the smooth displacement adjustment (SDA) method and the surface controlled overbending (SCO) method to optimize the tool shape for a forming process, in order to increase the geometry accuracy of the product after springback. The authors of [14] proposed a springback compensation method for singly curved products which are established based on the numerical solution of springback behavior. Numerical methods generally present a reliable prediction of the resultant outcome of a given forming process, although their use requires the creation of an appropriate model, which easily becomes a complex process due to the need to adjust multiple parameters. Furthermore, the process of creating and running models to achieve results can be a time-consuming task and demands a high computational cost, especially for complex models and when modifications are required to evaluate various alternatives [15,16].

Recently, there has been an increasing use of machine learning (ML) algorithms in various applications related to sheet metal forming to improve decision making and achieve cost-effective, defect-free, and optimal manufacturing quality $[17,18]$. The ML algorithms can be divided mainly in three categories: supervised learning, unsupervised learning [19], and reinforcement learning [20]. Generally, supervised learning is preferred and is used in classification or regression problems, encompassing support vector machine (SVM) algorithms, naive Bayes classifier, decision tree, the $K$-nearest neighbor $(K N N)$ algorithm and artificial neural networks (ANN). The authors of [21] used SVM to estimate the springback of a micro W-bending process with high prediction accuracy and generalization performance. The authors of [22] compared the performance of different machine learning algorithms (multilayer perceptron type ANN, random forest, decision tree, naive Bayes, $\mathrm{SVM}, \mathrm{KNN}$, and logistic regression) in predicting springback and maximum thinning in two different forming geometries, namely U-channel and square cup. The authors concluded that the multilayer perceptron algorithm was the best in identifying the springback, with a slightly higher score than SVM.

Artificial neural networks, among the various types of learning algorithms, are widely used in sheet metal forming processes due to their ability to overcome the limitations imposed by nonlinearities and the multiple parameters involved in forming problems. Several articles on air bending have been published, following the use of artificial neural networks [23-27]. The authors of [28] studied the use of ANN on modeling the air Vbending processes using both an analytical and experimental data set and demonstrated the capability of ANN to model the springback problem. The authors of [29] implemented a neural network in order to predict the stepped binder force trajectory for different punch displacements, in a plane strain channel forming process. The authors of [30] evaluated the applicability of ANN to the problem of choosing a tool geometry to bend a component with a defined shape. A finite element model created to simulate the bending process and a genetic algorithm (GA) were used to optimize the weights of an artificial neural network, thus reducing the deviation between the predicted tool and the experimental solution. The authors of [31] analyzed the performance of a multilinear regression model and an ANN in predicting the springback angle in air bending processes. The results show ANN outperforming the regression models approach for the evaluated cases. The authors of [32] also investigated the effect of bending and springback angles in bending processes. In this case, experimental data obtained from FEA models was used to design and train the developed ANN models. The results confirm the validity of the FEA analysis and consequently their capability to provide data for developing ANN. The authors of [33] developed a combination of error backpropagation neural network and spline function (BPNN-Spline) in order to estimate the springback angle in a V-die bending 
process. The results showed that the proposed BPNN-Spline model outperforms the traditional ANN in predicting the bending angles for different punch displacements. The authors of [3] developed a methodology based on ANN and FEA, capable of establishing the specific punch displacement for bending a sheet metal material according to the desired forming angle in press brake bending. The results showed that the developed methodology can successfully predict the required punch penetration to achieve a given bending angle by considering results both for geometry after springback and also geometry before springback. More recently, the authors of [34] proposed a novel theory-guided regularization method for deep neural network (TG-DNN) training, which uses the material Swift's law as the guidance to predict the deformed workpiece geometry after springback and the corresponding forming parameter of loading stroke. The authors conclude that the proposed TG-DNN outperforms the conventional pure data-driven DNN for its superior generalization accuracy, especially when only scarce and scattered experimental data are available for training.

In all these studies, the material is known and its mechanical characterization is described usually through work hardening laws (e.g., Swift law), determined in advance. Thus, the bending test is not usually the preferred method to determine experimentally the hardening behavior of a given material and normally tensile tests are used to determine such behavior. It is known that bending tests entail inhomogeneous stress and strain distributions in the material, making it impossible to infer the stress-strain relationship directly from the experiment [35]. Typically, the material parameters identification is performed by inverse methodologies where the objective is to find the parameters that provide an optimal fit for a wide range of experiments. The main drawback of this strategy is being time-consuming, particularly when several test conditions are used [36]. Recently, neural networks have been used to replace or improve the constitutive model obtained by inverse analysis [36-40]. For example, [41] developed a machine-learning based JohnsonCook (JC) plasticity model to capture the non-monotonic effect of the temperature and strain rate on the hardening response for DP800 steel. The authors concluded that by combining the neural network and existent material model, all the experimental data were described with high accuracy. None of these studies, however, are directly connected to the use of the bending process to evaluate a material hardening behavior. This paper thus appears as an attempt to respond to this research opportunity.

The purpose of the current study is to evaluate the applicability of machine learning algorithms on bending procedures. Therefore, different ANN will be developed in order to explore the modeling capabilities and to resolve two different problems directly related to bending solicitations herein called Problem (a) and Problem (b). Problem (a) is related to using neural networks to determine the hardening behavior of a given material using only the three-point bending test results. On a different perspective, Problem (b) is related to the implementation parameters of the air bending process where it is intended to develop a methodology that estimates the punch displacement required to obtain a given bending angle. In both approaches it is proposed to combine the use of a learning tool with a simulation and data generation tool (FEA) in order to train the developed ANN.

This paper is organized as follows. In Section 2, we provide an overview of the corresponding problem statements and establish the adopted methodologies to solve both problems. In Section 3, we include the neural network formulation and the implementations that showed the best performance. In Section 4, the neural network results obtained for the two problems are analyzed and discussed. 


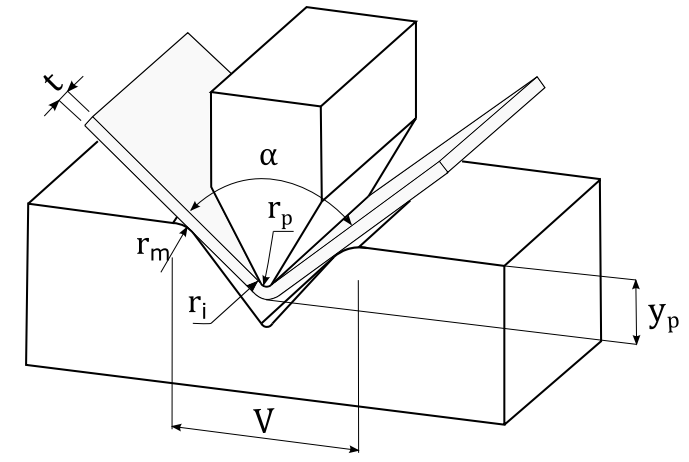

(a)

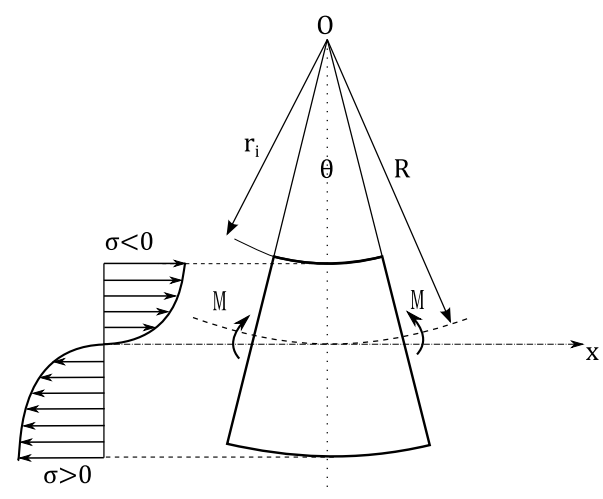

(b)

Figure 1. (a) Air bending process parameters: die opening $(V)$, die radius $\left(r_{m}\right)$, inside bending radius $\left(r_{i}\right)$, punch nose radius $\left(r_{p}\right)$, punch penetration $\left(y_{p}\right)$, sheet bending angle $(\alpha)$, sheet thickness $(t) ;(\mathbf{b})$ stress distribution in plastic bending deformation.

\section{Materials and Methods}

\subsection{Problem Statement}

Air bending is one of the most frequent plastic deformation methods used on parts made from flat sheets. As represented in Figure 1a, the main objective of this process is to obtain a desired bending angle, $\alpha$, in a sheet metal material by applying a specific punch displacement, $y_{p}$. The main process parameters include: (a) the tools geometry, which comprises the die opening, $V$, die radius, $r_{m}$, and punch radius, $r_{p} ;(b)$ the blank material, which includes not only the sheet thickness, $t$, but also the material properties (e.g., type of material, hardening law, yield stress, ultimate tensile strength, elongation) [3].

When a sheet metal material is bent, it is subjected to different stress stages throughout its depth (Figure 1b). The applied moment, $M$, causes the sheet to take the form of an arc of a circle centered at point $O$ with a radius $r_{i}$. On the convex side, the longitudinal fibers expand, and on the concave side, they compress. These two types of fibers are separated by a third set of fibers that retain their initial length and constitute the so-called neutral axis. The neutral axis divides the straight section into two parts: one part in tension $(\sigma>0)$, and one in compression $(\sigma<0)$. On the neutral axis the longitudinal stress is zero $(\sigma=0)[4]$.

As mentioned earlier, the springback effect plays an important role in bending processes. As represented in Figure 2 the removal of the tools leads to elastic recovery of the material, which results in different bending angles before and after springback. The springback angle, $\Delta \alpha_{S B}$, corresponds to the difference between the angle after elastic recovery, $\alpha_{f}$, and the bending angle defined when the punch contacts the part, $\alpha_{i}$. The springback is entirely intercorrelated with the stress distribution on sheet metal as residual stresses [42]. Its behavior is also affected by material properties such as strain hardening, elastic property evolution, the presence of Bauschinger effects, elastic and plastic anisotropy, and tribology between contacting surfaces [43]. Although there are mathematical models for predicting springback in bending situations, most of them are simplistic and do not take into account all influential factors. 


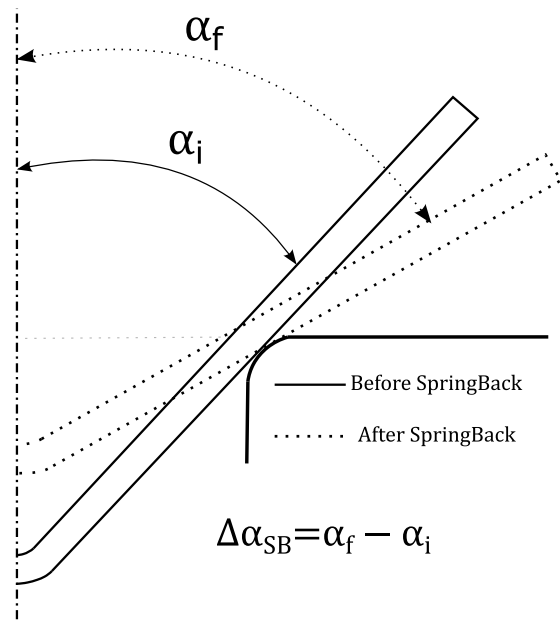

Figure 2. Definition of elastic recovery (springback) in bending process.

\subsubsection{Problem (a)-Material Characterization}

The three-point bending test [44] is a classic experiment used to evaluate the behavior of a material when subjected to bending. This test is in every way similar to the air bending process, as represented in Figure 3, however the main objective within this test will be to evaluate the behavior of a certain material to pure bending loading. This test is quite simple, as it does not require any prior sample preparation (e.g., machining), and can easily be performed on a universal tensile testing machine. The challenges with this test resides in the involvement of axial and transverse forces in the bending deformation. Furthermore, friction and local deformation beneath the contact points can also affect the results [45]. To convert the measured output from these tests (punch displacement, $y_{p}$ and punch force, $\left.F_{p}\right)$ into stress-strain $(\sigma-\varepsilon)$ response, inverse fitting models are usually used in literature [46-48]. These methods require accurate modeling of the test with a predetermined hardening model and costly optimization loops. The main drawback of this strategy is being time-consuming, particularly when several experimental tests are used. Another way is by using analytical approaches as for example the derivation proposed by [49].
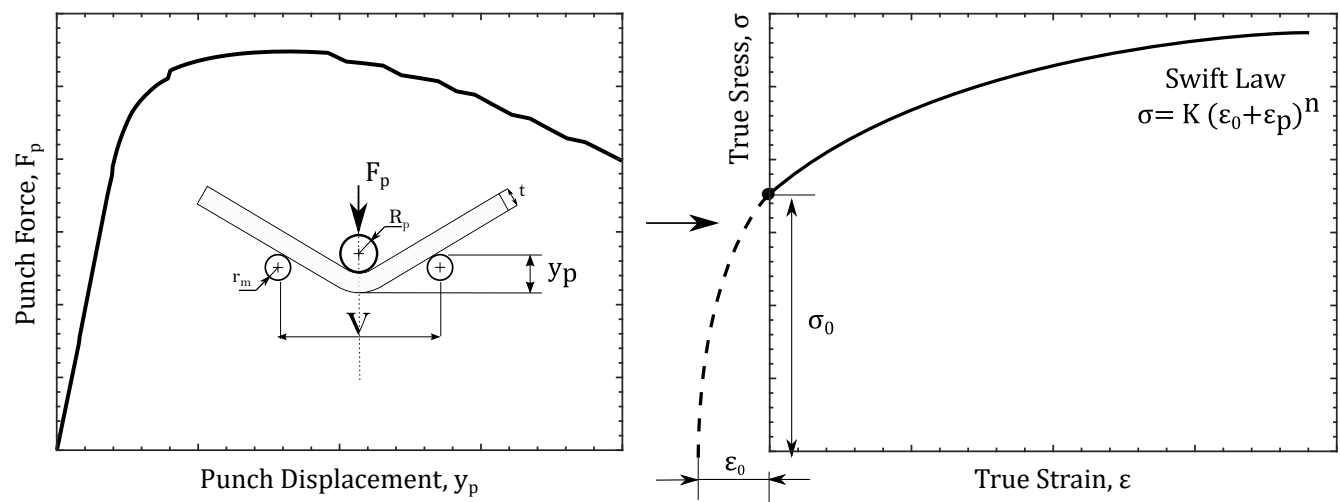

Figure 3. Schematic illustration of the three-point bending test and definition of the main objectives for problem (a).

The objective of this first problem is to develop a new methodology based on neural networks to characterize the hardening behavior of a material using the results obtained in a three-point bending test. Accordingly, it is proposed to implement a new procedure to replace the traditionally inverse and analytical fitting methods in order to easily characterize the hardening behavior of given material. The developed neural networks should consider as input the punch force displacement curve obtained in a three point bending test and provide the characteristic parameters of a Swift hardening law, as represented in 
Equation (1). The methodology should characterize materials with a $K$ parameter between [400-1600] and $n$ parameter between [0.05-0.35]. These limits are consistent with the objectives of characterizing materials widely used in industrial applications such as sheet metal steel, ranging from mild steels to AHSS. Accordingly, these parameters for $K$ (strength coefficient) and $n$ (work hardening exponent) will include every behavior for materials of interest, both for strength and also for different hardening behavior. In this problem, the value of $\varepsilon_{0}$ was taken as fixed with a constant value of 0.01 . Additionally, only $0.8 \mathrm{~mm}$ sheet thickness will be considered. The Swift law parameters and their limits considered in this bending problem (a) are summarized in Table 1. This table also includes the geometry of the chosen setup to perform the three-point bending test.

$$
\sigma=K\left(\varepsilon_{0}+\varepsilon_{p}\right)^{n}
$$

Table 1. Swift parameters and bending test geometry used in problem (a).

\begin{tabular}{cccccc}
\hline & Swift Parameters & \multicolumn{3}{c}{ 3-Point Bending Test Geometry } \\
\hline $\boldsymbol{K}$ & $\boldsymbol{n}$ & $\varepsilon_{\mathbf{0}}$ & $\boldsymbol{R}_{\boldsymbol{m}}[\mathrm{mm}]$ & $\boldsymbol{R}_{\boldsymbol{p}}[\mathrm{mm}]$ & $\boldsymbol{V}$ [mm] \\
\hline $400-1600$ & $0.05-0.35$ & 0.01 & 4 & 4 & 50 \\
\hline
\end{tabular}

\subsubsection{Problem (b)_Air Bending, Forming and Springback Prediction}

The second problem of this work will address the air bending process, considering the influence of springback on the process. As referred, the major advantage of this bending technique is the ability to use the same set of tools (punch and die) to achieve multiple bending angles in different materials. In this context, establishing and controlling the amount of punch penetration becomes the most important process parameter to establish and control. However, obtaining the required bending angle with adequate accuracy can become a major challenge due to the many parameters involved in the process. The main objective of Problem (b) is the development of a new methodology based on neural networks to estimate the required punch displacement, $y_{p}$, to produce a given bending angle, $\alpha$, using well-defined process conditions. These bending conditions include not only the tools geometry $\left(V, r_{m}, r_{p}\right)$ but also the material thickness, $t$.

Due to the problem's geometric simplicity, analytical relationships involving variables in the bending process, such as punch displacement as a function of bending angle, die radius, die opening, and sheet thickness, can be defined. Previous research has shown that J. Bessa Pacheco's analytical model $\left(Y_{J B P}\right)$ [8] is the one that best reproduces the behavior $\left(y_{p}=f(\alpha)\right)$ seen in press brake air bending. This proposal, represented in Equation (2), incorporates the sheet metal thickness $(t)$, bending angle $(\alpha)$, die opening $(V)$, inside bending radius $\left(r_{i}\right)$, and die radius $\left(r_{m}\right)$ and will be utilized as a supplement to the results analysis in the current work.

$$
Y_{J B P}=\frac{V}{2 \cdot \tan \left(\frac{\alpha}{2}\right)}+\left(r_{i}+t+r_{m}\right) \times \frac{1-\sin \left(\frac{\alpha}{2}\right)}{\sin \left(\frac{\alpha}{2}\right)}
$$

The die opening is a significant influencing factor in the bending process. The typical bender's practice is to choose the die opening based on the sheet thickness. The ideal combination of sheet thicknesses and die opening can be defined by practical guidelines derived from industrial process experience. Linear relationships between those variables (Equation (3)) characterized by a scalar $k_{v t}$ factor can be utilized to determine the boundaries of suitable combinations. Normally, $k_{v t}$ factors with values between 6 and 10 establish the limits of appropriate combinations for a correct bending operation.

$$
V=k_{v t} \cdot t
$$

Figure 4 represents industrial practices for press-brake bending, in which standard die dimensions ( $V$ opening) are considered $(V=11.5,18.3,23.1,34.2,43.7,53.7 \mathrm{~mm})$ and 
the intended sheet metal thickness ( $t$ between 0.5 and $6.0 \mathrm{~mm}$ ) for practical applications. It is seen also in Figure 4 the recommended industrial practice of $V / t$ ratios between 6 and 10, a region defined by such straight lines. Press-brake bending performed outside this region of recommended ratios will either give rise for high springback results (case A, $V / t>10$ ) or punch indentations (case $\mathrm{C}, V / t<6$ ). A recommended ratio is represented by case $\mathrm{B}$, for a $6<V / t<10$. Accordingly, when comparing cases $\mathrm{A}$ and $\mathrm{B}$ the same die is used $(V=43.7)$ for a thickness of $1 \mathrm{~mm}$ (non-recommended $V / t=43.7$ ) and $5 \mathrm{~mm}$ (recommended $V / t=8.7$ ); as a consequence it is seen an excessive curvature geometry for case $\mathrm{A}$, thus resulting an higher springback, after bending. This also means that when comparing these two situations, case A (non-recommended $V / t$ ) will have a different relation between bent angle and punch penetration when compared to case B (recommended $V / t)$. On the other hand, $V / t$ ratios less than 6 should be avoided since greater pressures are created at tool/blank interfaces, and localized deformations (i.e., indentations) emerge at such contact zones, increasing the probability of fracture. For example, comparing cases $C$ and $\mathrm{B}$, the same sheet thickness is used $(t=5 \mathrm{~mm})$ to be processed by different die openings: case B uses $V=43.7 \mathrm{~mm}$ (recommended $V / t=8.7$ ), while case $C$ uses $V=23.1 \mathrm{~mm}$ (nonrecommended $V / t=4.6$ ). It is seen (Figure 4 ) that for case $C$ the punch indents the material, causing a superficial defect and also contributing to a different relation between bent angle and punch, when compared to recommended case B.
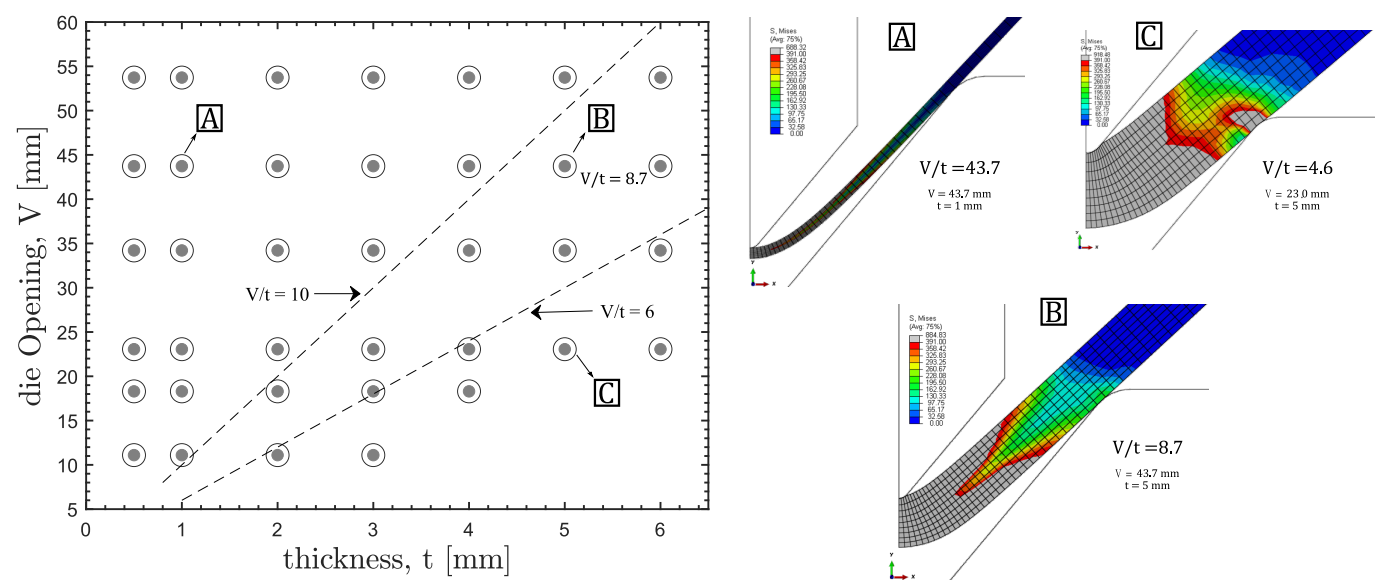

Figure 4. $V$ - $t$ diagram: combinations of tested $V$ and $t$ values (points) and limits (straight lines) representing industrial practice reference rules.

The influence of springback in the $y_{p}-\alpha$ relation, for $A, B$, and C is represented in Figure 5. In each graph it is presented the punch displacement, $y_{p}$, needed to produce a desired bending angle, $\alpha$, between $90^{\circ}$ and $180^{\circ}$ and considering two distinct situations: before and after springback. This representation confirms that the springback effect is more evident for case A since the difference between the punch displacement before and after springback is higher. Thus, in this bending condition the springback need to be taken into account when predicting the punch displacement, in order to achieve a proper bending result. In addition, the punch displacement predicted by the $Y_{J B P}$ analytical model is also shown, for each case, in Figure 5. Generally speaking, the analytical model prediction is in closer agreement with the numerical reference value before springback for all cases. This is quite expected since the mathematical formulation of this model only includes the tool geometry and the material sheet thickness, ignoring the springback effect. Thus, the results obtained using the analytical approach are suitable for regions with reduced springback effect $(V / t<10)$ while for higher ratios the accuracy of results is reduced. Nevertheless, even for this zone $(V / t<10)$, the analytical approaches can be synonymous of errors. 
Case A

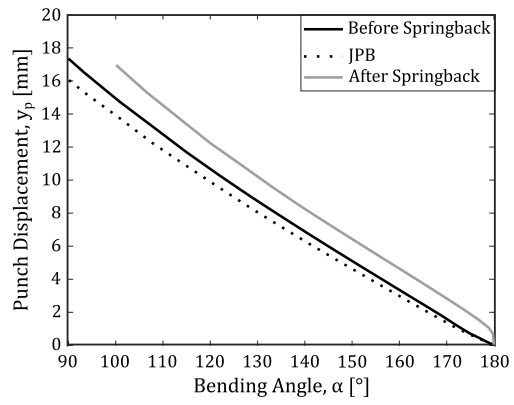

Case B

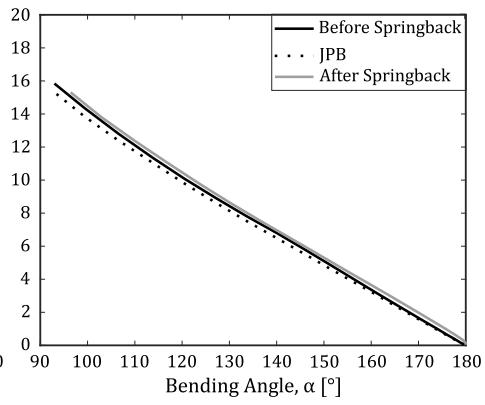

Case C

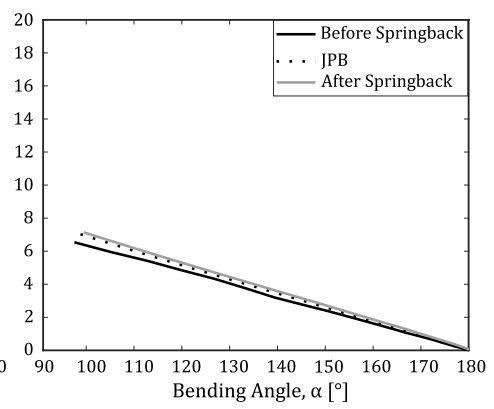

Figure 5. Punch displacement $\left(y_{p}\right)$ graphs as a function of required bending angle $(\alpha)$ for cases A-C.

The springback angle, $\Delta \alpha_{S B}$ is represented in Figure 6 for different $V / t$ ratios and assuming different desired bending angles, $\alpha$. The values for the cases $\mathrm{A}$ and $\mathrm{B}$ are also represented. This representation reinforces that higher $V / t$ ratios promotes the material elastic recovery, which is translated in a higher difference between the angle before and after tooling removal. Additionally, it is visible that springback angle increases during the bending operation. Therefore, for a final bending angle of $90^{\circ}$, the springback angle for cases $\mathrm{A}$ and $\mathrm{B}$ are $14^{\circ}$ and $3^{\circ}$ respectively.

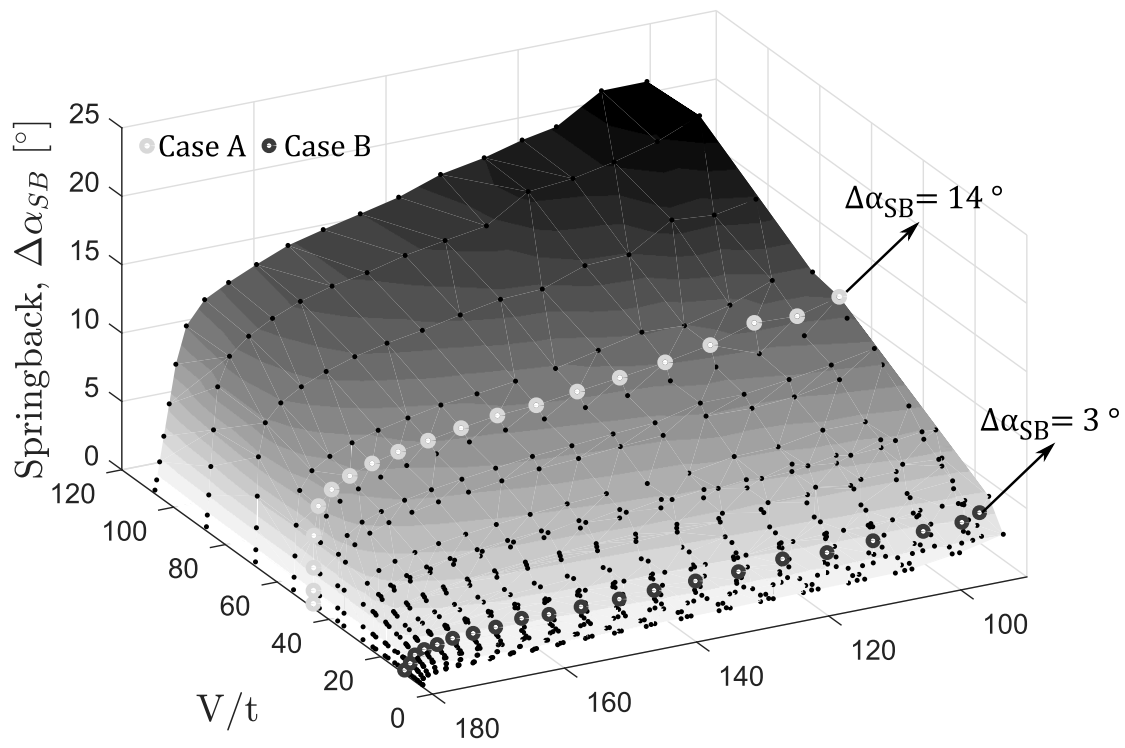

Bending Angle, $\alpha\left[^{\circ}\right]$

Figure 6. Springback angle values $\left(\Delta \alpha_{S B}\right)$ for different bending conditions ( $V / t$ ratios) and considering different required bending angles $(\alpha)$.

To sum up, the air bending problem (b) of this work aims to develop a method capable of providing a fast and accurate estimate of the punch displacement, $y_{p}$, to obtain a desired angle $\alpha$ for the complete range of $V / t$ ratios presented in Figure 4. The developed neural networks should not only present the punch displacement for a desired bending angle but also an estimate of a springback angle for each case. For such purpose, only one material will be considered, a dual phase steel (DP590) with thicknesses between $0.5<t<6 \mathrm{~mm}$. The die opening values considered are defined between $10<V<50 \mathrm{~mm}$ which translate in a "die opening-thickness" ratio between $1.6<V / t<100$. The selected die openings $(V)$ correspond to dimensions for standard industrial press-brake bending dies and the sheet metal thicknesses represent the most common practical intended applications. 


\subsection{Proposed Approach Using ANN}

Modeling and solving a problem using artificial neural networks (ANN) can be included within machine learning (ML) approaches, as its development is based on the available data that characterizes the problem. Most often, the ANN algorithms consist of a supervised learning method, although unsupervised ANN algorithms are also used. Considering its widespread interest and use since mainly the late 1980s [50,51], currently, there has been a renewed interest due to the latest developments associated with, which is normally referred to as deep learning, or deep neural networks (DL/DNN) [52]. These DNN entail an increased complexity of the models and have been successful in numerous pattern recognition problems. In the present work we will be concentrated on a conventional ANN approach, i.e., shallow ANN, rather than on DNN which we believe will be of interest when escalating the approach to a higher scale of generalization ability.

The main idea behind ANN, either shallow or deep models, is a structure of multiple simple processing elements (PE), or nodes, with a pattern of interconnections (weights) that process information at its input to provide a solution, to the problem, at its output. As such, it is usually characterized as being inspired in the human brain. In a supervised learning algorithm the process of learning consists on the adjustment of parameters (i.e., weight's values of the interconnections) in order to minimize an error function that represents a measure of the deviation between the known, or target response, and the ANN response, when examples, or instances of the problem are available in the data sets. A typical ANN architecture is represented in Figure 7 where the nodes (i.e., PE) are organized in successive layers from Input to Output, and without backwards connections, i.e., in a feedforward structure [50]. The use of nonlinear functions in the PE, combined with multiple PE, enables ANN to model highly nonlinear problems. The definition of the Input and Output layers defines how the problem is formulated and encoded in the ANN. This structure provides great flexibility by allowing the combination of different types of information we can give to a single ANN, as well as enabling multiple types of information a single ANN can provide to the user. Before an ANN can be ready to provide a solution in a use phase, its variable parameters must be adjusted in a training, or learning phase. This requires the selection of the performance function and the algorithm used to minimize this function by selecting the appropriate values for each adjustable parameter. Multiple algorithms can be used, being most common backpropagation or gradient descent based learning methods and the mean squared error (MSE) as the performance function, namely in function approximation type problems. Having the ANN architecture defined and the training phase completed, the ANN represents a well-defined mathematical function that delivers output values when input values are specified. The ANN developed in the present work for both problems were based on this architecture. As represented in Figure 8 for problem (a) the objective is to define and encode at the input layer, information relative to the force-displacement $\left(F_{p}-y_{p}\right)$ bending test, in order to obtain at the output layer the parameters of the constitutive hardening law -Equation (1). In problem (b) the objective is to define at the ANN input layer the die opening $(V)$, the material thickness $(t)$ and the desired bending angle $(\alpha)$ and having at the ANN output the punch displacement $\left(y_{P}\right)$ that should be used and the magnitude of the springback angle $\left(\Delta \alpha_{S B}\right)$. Both problems were considered as function approximation type problems. The required training and validation data sets were obtained through the use of FEA models, as described in the next section. 


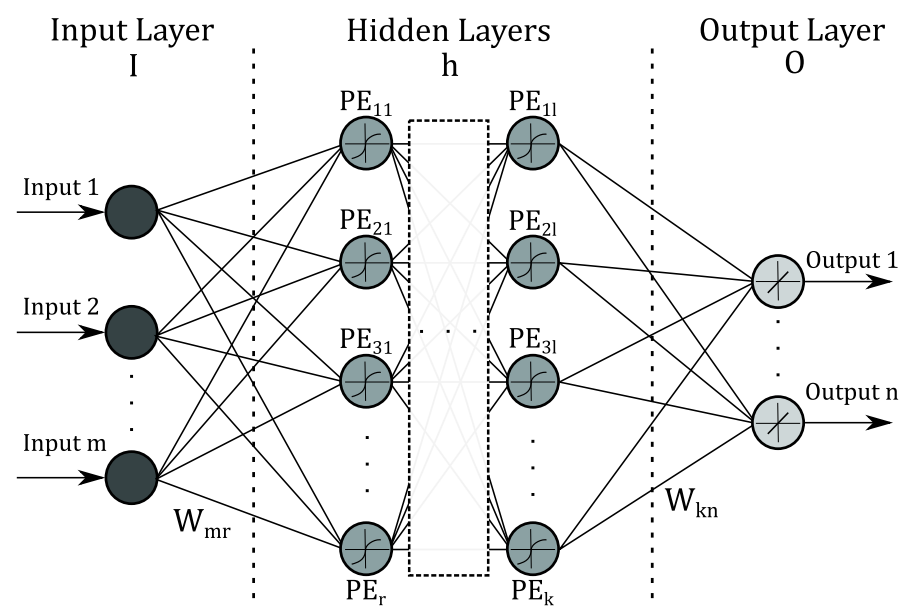

Figure 7. Neural network: example of a feedforward structure, with $m$ input nodes, several hidden layers with specific numbers of processing units (PE) each implementing a nonlinear function (i.e., sigmoid), $n$ output nodes implementing a linear function and interconnections weights (i.e., $W_{k n}$ and $\left.W_{m r}\right)$.

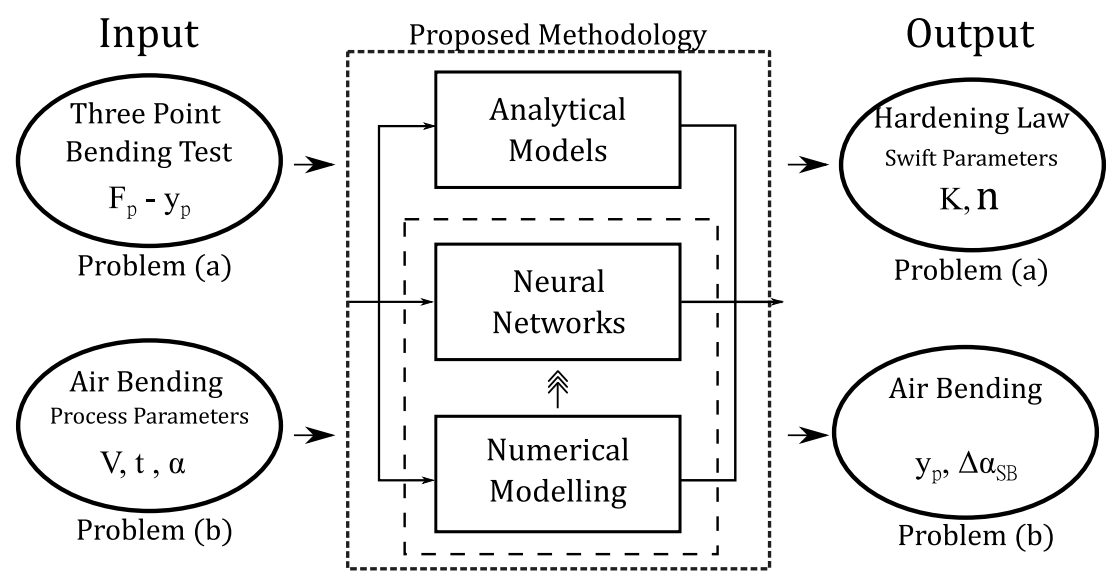

Figure 8. Schematic representation of the main objectives and the proposed methodology for solving problems (a) and (b).

\subsection{Finite Element Model}

The air bending process and the three point bending test can be defined as plane strain problems, in which the blank width is much larger than the blank thickness. Due to the symmetry of these two proposed bending processes, only half of real experimental setup was considered in the 2D finite element model. Figures 9 and 10 illustrates the fundamental geometry and variables defined for FE models, used for the bending problem (a) and press-brake bending problem (b), respectively. Both numerical models were validated by experiments in previous works $[3,53]$.

\subsubsection{Problem (a)-Material Characterization}

The three-point bending process simulation, problem (a) was performed using ABAQUS with implicit analysis (ABAQUS/ Standard). The blank material is modeled with an elastoplastic behavior using the Swift law for the hardening curve. The selected materials and corresponding properties are presented in the Table 2 . The sheet blank was discretized with 819 deformable four node solid elements (CPE4R type from ABAQUS Library) and nine layers through thickness. Mesh discretization is regularly spaced in both thickness and length (xx-axis) directions. Punch and die were modelled as analytical rigid surfaces and for Coulomb friction a value of 0.1 has been defined, which follows previous results obtained from experiments validating the numerical model [53]. 


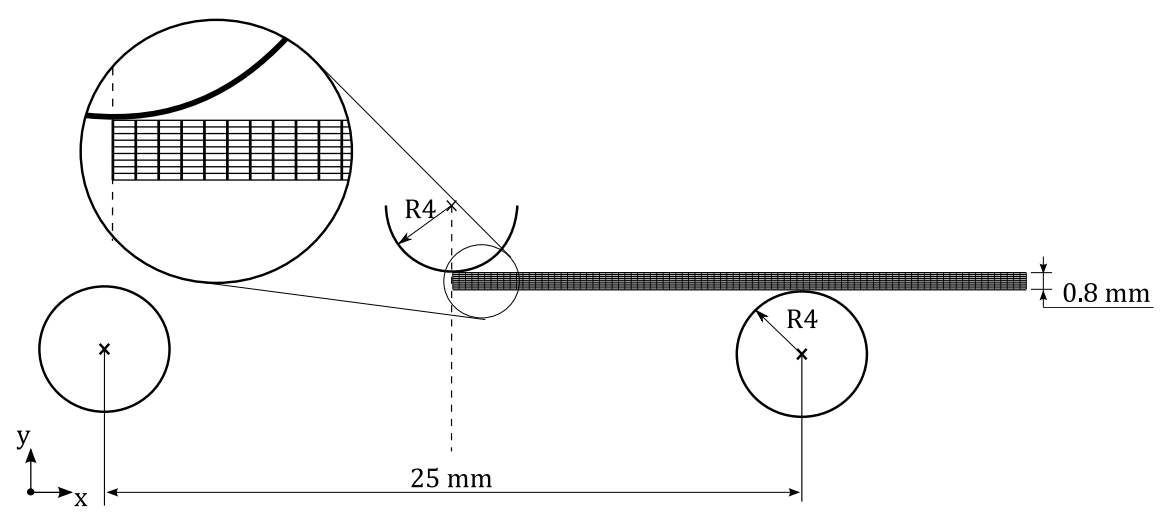

Figure 9. Three-point bending test geometry and variables defined for problem (a) FE model.

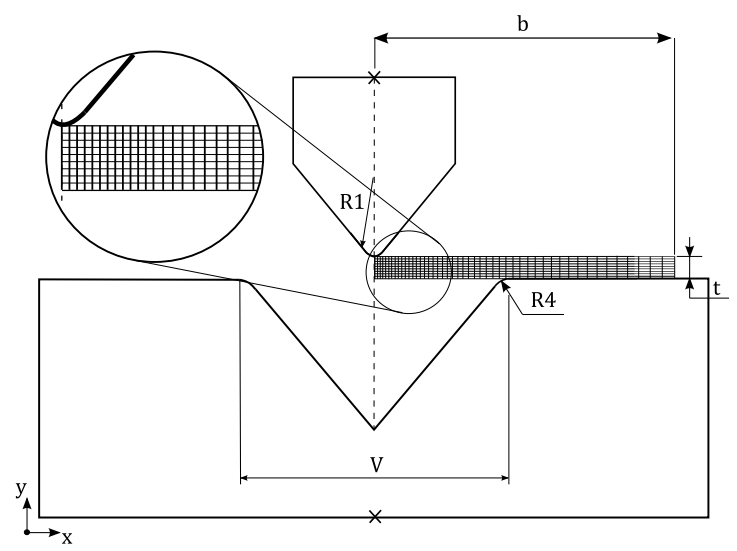

Figure 10. Geometry and variables defined for problem (b) FE model.

Table 2. Mechanical properties and Swift law hardening parameters of selected materials used in problem (a).

\begin{tabular}{ccc}
\hline Property & & \\
\hline Elastic modulus & E [GPa] & 210 \\
Poisson coefficient & $v$ & 0.3 \\
\hline & $K$ & $400-1600$ \\
Swift parameters & $\varepsilon_{0}$ & 0.01 \\
$\sigma=K\left(\varepsilon_{0}+\varepsilon\right)^{n}$ & $n$ & $0.05-0.35$ \\
\hline
\end{tabular}

\subsubsection{Problem (b)-Air Bending: Forming and Springback Prediction}

The press-brake air bending process simulation, problem (b) was performed using ABAQUS with implicit analysis (ABAQUS/ Standard) for this quasi-static problem. Therefore, both the bending process and the springback can be processed efficiently by using two steps for simulation. The blank material, dual-phase steel DP590, is modeled with an elastoplastic behavior using the Swift law for the hardening curve. The selected materials and corresponding properties are presented in the Table 3 . The sheet blank was meshed with 450 deformable four node solid elements (CPE4R type from ABAQUS Library) and nine layers through thickness. Mesh discretization along $x x$ direction is done with a bias ratio, so that several nodes accommodates to a small punch radius but also a similar ratio accommodates to a higher die radius, always having in mind a right balance with proportion for elements. Punch and die were modelled as analytical rigid surfaces. The friction has been considered for the interacting surfaces, with a Coulomb coefficient of 0.15 , following previous results with experiments to validate the numerical model [3]. 
Table 3. Mechanical properties and Swift law hardening parameters of selected materials used in problem (b).

\begin{tabular}{ccc}
\hline Property & & DP590 \\
\hline Elastic modulus & E $[\mathrm{GPa}]$ & 210 \\
Poisson coefficient & $v$ & 0.3 \\
Yield stress & $R_{e}[\mathrm{MPa}]$ & 393 \\
Ultimate tensile strength & $R_{m}[\mathrm{MPa}]$ & 641 \\
Total elongation & $e_{t}[\%]$ & 26 \\
\hline & $K$ & 1000 \\
Swift Parameters & $\varepsilon_{0}$ & 0.0024 \\
$\sigma=K\left(\varepsilon_{0}+\varepsilon\right)^{n}$ & $n$ & 0.155 \\
\hline
\end{tabular}

Python scripts were developed to create and modify automatically the parts of finite element model, for different bending conditions and also to submit the analysis, since a total of 740 analysis were considered. In order to acquire results from each of previous numerical simulations, an additional python script was written so that the fundamental data is retrieved for the ANN development such as punch displacement, bending angle, bending conditions and other variables.

\section{Neural Networks Implementation}

Once a specific architecture is selected, developing an ANN solution involves mainly an iterative process of specifying values for the variable parameters in the learning algorithms and evaluating the resulting performance, in order to select the best settings. Due to the high number of parameters involved, this development turns out to be a case dependent problem with few guidelines available to guarantee success in every case.

The first step is the generation and analysis of the data available for each problem. The higher the quantity of data available, the better are the expectations of developing a successful ANN solution. The data used should represent the variety of situations, i.e., instances, of the problem in order to obtain good generalization abilities. In order to promote these objectives data is normally divided in: data sets used during the learning phase for parameters adjustment (i.e., training sets) and data sets new to the ANN (i.e., test set). In some learning algorithms a third set is used (validation set), not for parameters adjustment, but to favor ANN generalization capability, by stopping training when performance deteriorates in the validation set (early stopping).

Analyzing the data is also crucial, especially in shallow ANN, as it may enable reducing the number of elements required to represent the information in the Input layer and therefore the size of the ANN. A good knowledge of the problem is also important to interpret and define the Output layer elements required. The next sections describe the specific problem formulation and respective ANN implementation using the Deep Learning Toolbox available in Matlab [54].

\subsection{Problem (a)-Material Characterization}

In this problem, the input data, provided by FEA, consists of a punch force-displacement, $F_{p}-y_{p}$, curve comprising a total of 730 discrete points. In feedforward shallow ANN, each layer is fully connected to the next layer, which in this problem makes unpraticable to use all points as elements in the Input layer. So, in order to simplify the ANN structure and reduce the number of parameters to be adjusted, only five points were considered as illustrated in Figure 11a. P1 corresponds to the point that divides the elastic deformation zone, characterized by a linear $F_{p}-y_{p}$ trend, from the plastic deformation zone on the test curve. On the other hand, P2 represents the point of maximum force in each test. Similarly, P3, P4 and $\mathrm{P} 5$ are points with arbitrarily chosen fixed displacement values $(15 \mathrm{~mm}, 17 \mathrm{~mm}, 20 \mathrm{~mm})$ used in each curve. Therefore, as represented in Figure 11b, the feedforward ANN for this first problem will be characterized by ten processing elements corresponding to the five pairs 
of punch force-displacement values in the input layer and two output values corresponding to parameters $K$ and $n$ of the Swift law, represented in Equation (1).

A total of 91 curves were generated considering 13 different values for $K$ parameter and 7 values for the $n$ parameter. These curves are obtained from bending tests having the same conditions for punch displacement, from $0 \mathrm{~mm}$ (flat sheet blank) to $20 \mathrm{~mm}$ (bent specimen). Figure 12 shows the data sets (output values) used for neural network development. It can be seen that the $13 K$ parameters were selected in the interval $[400,1600]$ with 100 units increments, and the $7 n$ values with increments of 0.05 units in the interval [0.05, 0.35]. From these, 55 cases $(60.4 \%$ of the total) were used as the training set. The remaining cases $(39.6 \%$ of the total), corresponding to $K=800, K=1400$ and $n=0.15, n=0.25$ were randomly split into a testing and validating set, each with 18 cases.

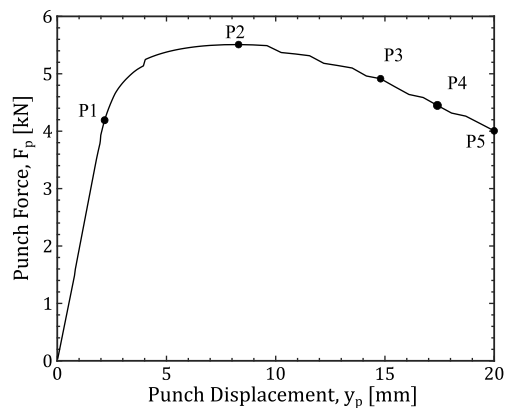

(a)

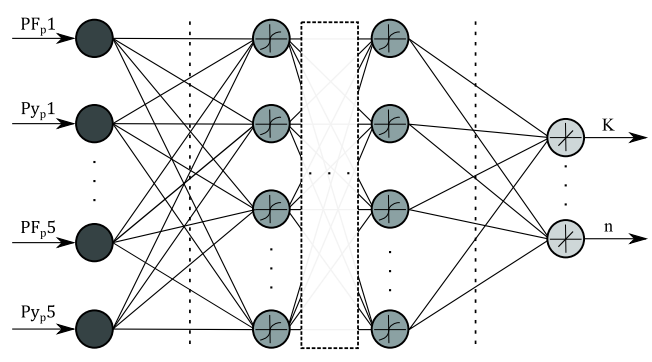

(b)

Figure 11. Implementation of material characterization problem: (a) punch force-displacement curve and the selected five pairs of values (P1-P5); (b) structure of the neural network with ten processing elements in the input layer corresponding to the five pairs of punch force-displacement values and two nodes in the output layer (Swift parameters $-K$ and $n$ ).

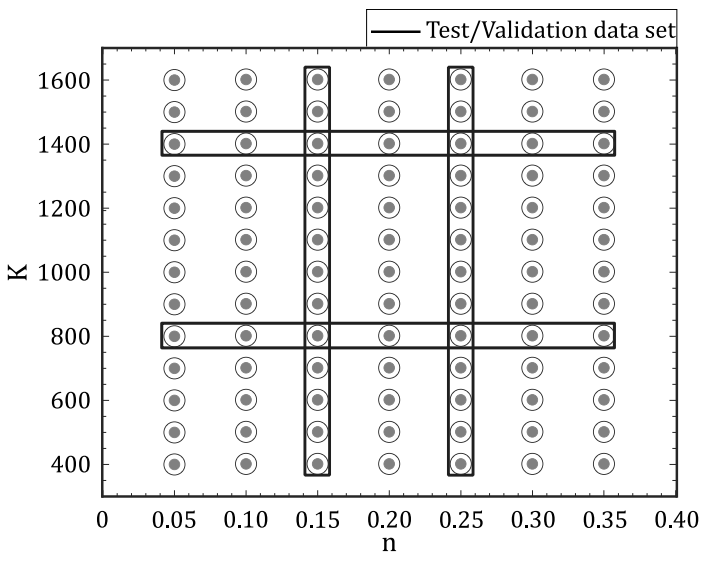

Figure 12. Selected data sets for problem (a).

Various combinations of hidden elements and layers were tested in multiple and repeated runs using the Levenberg-Marquardt learning algorithm and the mean squared error (MSE) performance function [55], in order to identify the size of the NN structure that seemed to fit better the available data. For the best performant cases, several runs (10) were made, starting with different initial weight values and initial learning rate parameters. The weight values were updated in a batch mode, i.e., after all data cases were presented to the ANN. The input and output values were normalized in the $[-1,1]$ range, and several learning parameter combinations were tested. The condition to stop learning was based on the performance function on the values of the validation set (i.e., early stop). The best performance was obtained with five hidden layers, each with five elements. Following the training phase, the ANN performance were compared against the simulation solutions, after conversion of the NNs output to un-normalized values. The performance obtained can 
be observed through the error's histograms in Figure 13, where the extreme error values appear on a reduced number of cases. Table 4 presents the performance of the developed ANN, after conversion to un-normalized values, for each of the three data sets (training, validating, and testing) and in terms of root mean squared error, RMSE-Equation (4), maximum and minimum extreme error values.

$$
\text { RMSE }=\sqrt{\text { MSE }}=\sqrt{\frac{1}{N} \cdot\left[\sum_{i=1}^{N}\left(\text { target }_{i}-\text { output }_{i}\right)^{2}\right]}
$$

In absolute terms it looks as the ANN performs worse in modeling the $K$ parameter comparatively to the $n$ parameter. However, when the performance measures, RMSE, are expressed in relation to the range values of each parameter (i.e., 1200 for $K, 0.3$ for $n$ ) and in relation to the $K$ and $n$ values for the maximum and minimum values, the performance is of similar magnitudes and behavior in the three data sets for both parameters. The overall performance (RMSE) is better in the training sets, less than $0.5 \%$ in both cases, with the validating and testing sets below $2 \%$ in the worst case. The extreme values are higher (i.e., $-8.6 \%)$, but they occur in a few cases.

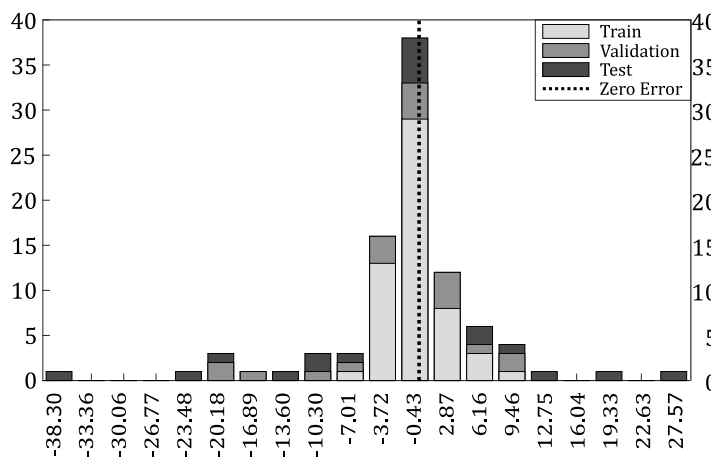

(a) $K$ error histogram

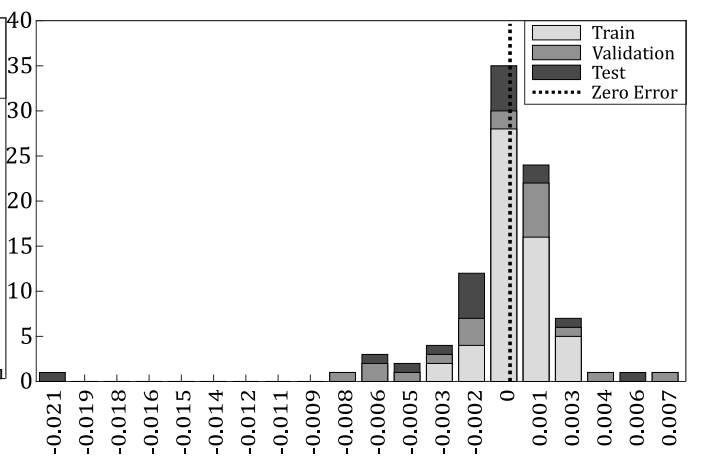

(b) $n$ error histogram

Figure 13. Neural network histogram of errors for (a) $K$ output variable and (b) $n$ output variable considering un-normalized values, all data sets and considering grouping each of the 91 cases error in 20 classes (i.e., bins).

Table 4. Neural networks performance error for problem (a) in terms of RMSE, Max. and Min.

\begin{tabular}{cccccccccc}
\hline & \multicolumn{3}{c}{ Training Data Set } & \multicolumn{3}{c}{ Validating Data Set } & \multicolumn{3}{c}{ Testing Data Set } \\
\hline & RMSE & Max. & Min. & RMSE & Max. & Min. & RMSE & Max. & Min. \\
\hline $\boldsymbol{K}$ & 2.959 & 9.508 & -7.938 & 8.955 & 10.201 & -21.225 & 15.376 & 27.567 & -38.296 \\
$\boldsymbol{n}$ & 0.0013 & 0.0031 & -0.0034 & 0.0037 & 0.0078 & -0.0081 & 0.0057 & 0.0051 & -0.0216 \\
\hline $\boldsymbol{K}$ & $0.3 \%$ & $0.6 \%$ & $-0.3 \%$ & $0.8 \%$ & $1.3 \%$ & $-2.7 \%$ & $1.3 \%$ & $1.7 \%$ & $-7.6 \%$ \\
$\boldsymbol{n}$ & $0.4 \%$ & $0.9 \%$ & $-3.4 \%$ & $1.2 \%$ & $5.2 \%$ & $-3.4 \%$ & $1.9 \%$ & $3.4 \%$ & $-8.6 \%$ \\
\hline
\end{tabular}

\subsection{Problem (b)-Air Bending: Forming and Springback Prediction}

In this work the advantages of formulating specific ANN modeling of forming and springback in air bending are highlighted by the possibility of extending the use of pressbrake variables ( $V / t$ ratios) outside the limits of practical industry guidelines that are mainly supported by analytical and experience based knowledge [3]. Furthermore, it is desired to explore whether a multitask versus single task ANN [34] can prove to be more effective in increasing the generalization ability and reduce errors and outliers. The additional information in the multitask ANN can also be considered of interest for the air bending application. The input layer includes the die opening $(V)$, the sheet thickness $(t)$ and the desired bending angle $(\alpha)$ (Figure 14) in both multitask and single task ANN. In one of the single task ANN the output layer consists on the punch displacement $\left(y_{p}\right)$ required 
to obtain the desired bending angle, after removing the tool (i.e., after springback occurred). Another single task ANN provides as output, the springback angle $\left(\Delta \alpha_{S B}\right)$. In the multitask ANN, the output includes, in addition to the punch displacement, the magnitude of the springback angle.

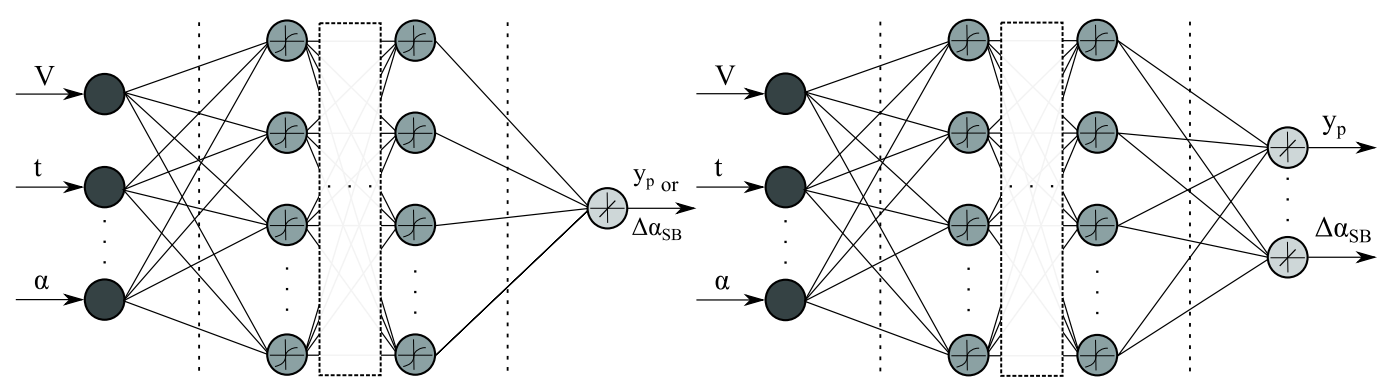

(a) Single-task (ST) ANN structure

(b) Multitask (MT) ANN structure

Figure 14. Structure of the neural networks considering (a) single task (ST) and (b) multitask (MT) formulations.

A total number of 37 cases were used (Figure 15) resulting from different combinations of die opening and material thickness (Table 5). Two different separations of data (DD1, DD2) between training and validation/testing sets were used in the multiple runs of ANN development stages. In both separations, the same proportion of training (25/37) versus validation/testing (12/37) was used. An automated Bayesian regularization learning algorithm using the respective learning function available in Matlab ('trainbr') [55] combined with early stopping, and the mean squared error (MSE) performance function, as it could enhance reduction of extreme errors.

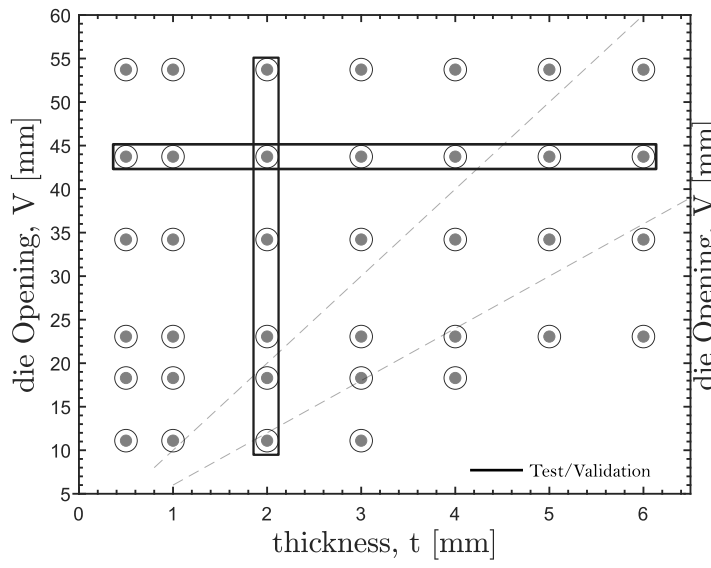

(a)

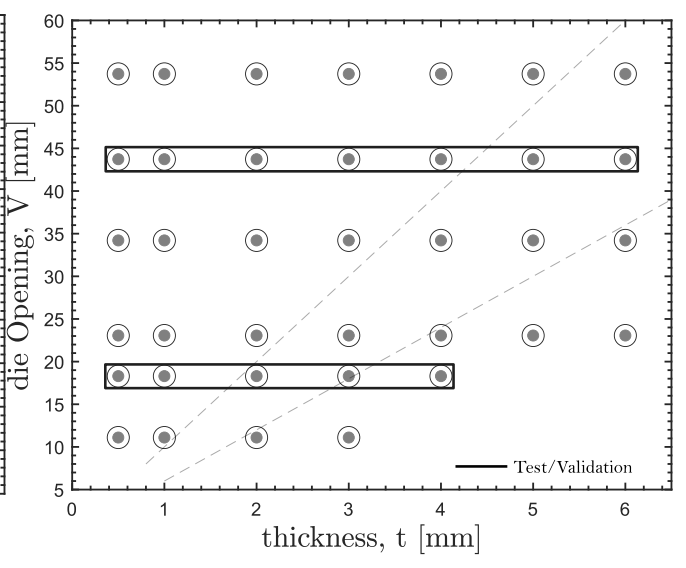

(b)

Figure 15. Selected bending processing conditions ( $V / t$ ratios) for (a) data set division I (DD1) and (b) data set division II (DD2).

The results obtained with the considered best performant ANN, either ST-NN, MT-NN and considering the two data divisions (DD1, DD2), are represented in Figure 16. The results include an overall measure (RMSE), maximum positive and minimum negative errors, for each used data set (training, validation, testing). When considering all measures, it can be observed that, for the punch displacement $\left(y_{p}\right)$, the performance on training, validation and testing data sets are in closer agreement for the MT-NN, although having slightly lower RMSE performance in the training set comparatively with the ST-NN. Combined with the general better performance on the outliers in all sets (training, validation, testing) it can be considered that a MT-NN generalizes better than ST-NN. When observing the results for the springback angle using the MT-NN, the same behavior is verified, with the MT-NN performing better and more homogeneously. However, the extreme error values 
occur in cases within the training set. These results will be further analyzed in the next section in order to evaluate the usefulness of the ANN models in both problems (a) and (b).

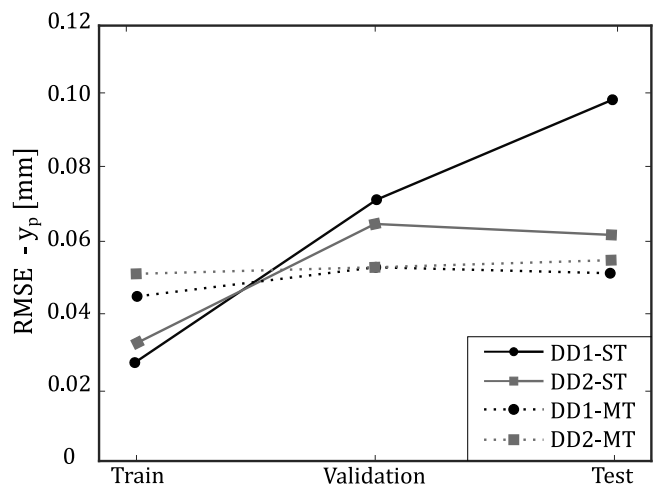

(a) RMSE - $y_{p}$

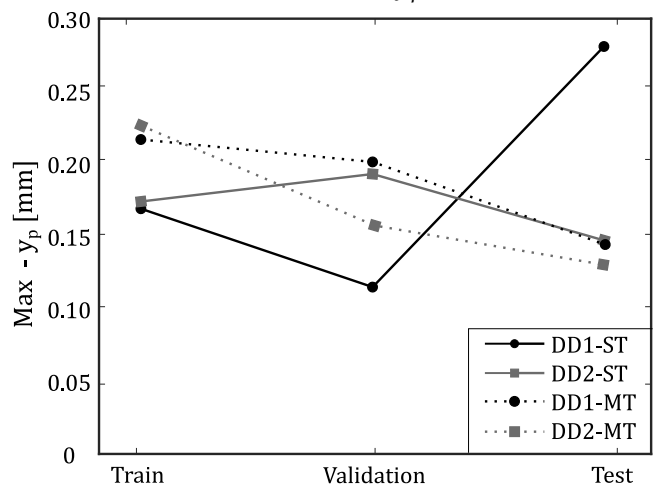

(c) Max - $y_{p}$

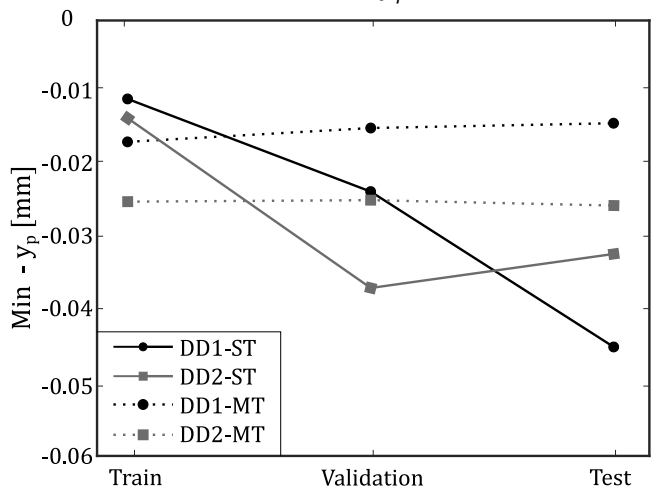

(e) Min - $y_{p}$

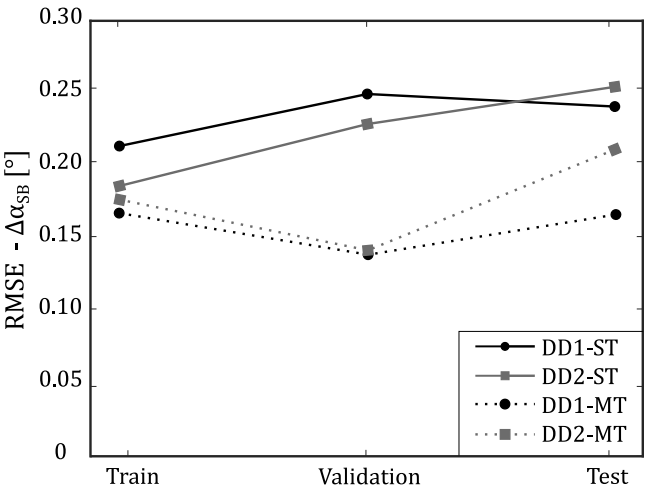

(b) RMSE - $\Delta \alpha_{S B}$

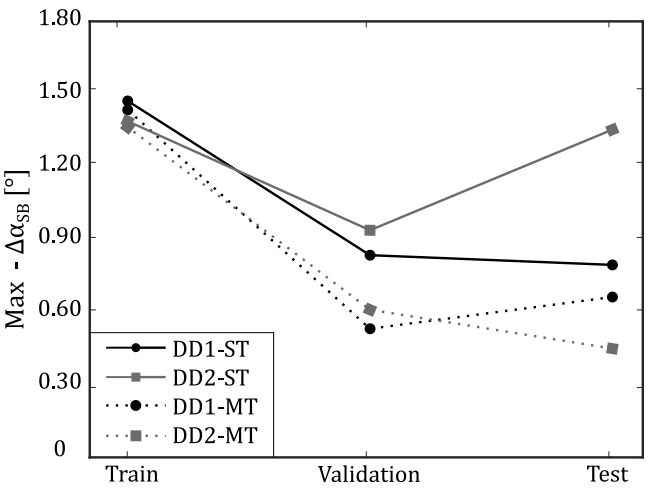

(d) $\operatorname{Max}-\Delta \alpha_{S B}$

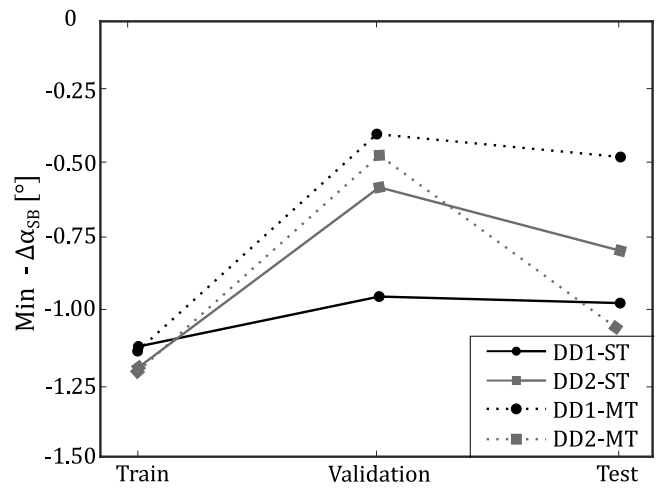

(f) Min $-\Delta \alpha_{S B}$

Figure 16. Performance measures of neural networks for the two different data sets (DD1 and DD2) and considering both single (ST) and multitask (MT) ANN structure; all performance measures are presented for the train, validation and test data sets; (a) punch displacement $\left(y_{p}\right)$ RMSE value; (b) springback angle $\left(\Delta \alpha_{S B}\right)$ RMSE value; (c) punch displacement $\left(y_{p}\right)$ maximum value; (d) springback angle $\left(\Delta \alpha_{S B}\right)$ maximum value; (e) punch displacement $\left(y_{p}\right)$ minimum value; (f) springback angle $\left(\Delta \alpha_{S B}\right)$ minimum value. 
Table 5. Test combinations and dimensions for the tooling used in problem (b).

\begin{tabular}{|c|c|c|c|c|c|c|c|c|c|c|}
\hline \multirow{2}{*}{$\begin{array}{c}\mathrm{V} \\
{[\mathrm{mm}]}\end{array}$} & \multirow{2}{*}{$\begin{array}{c}V_{\text {nom }} \\
{[\mathrm{mm}]}\end{array}$} & \multirow{2}{*}{$\begin{array}{c}\alpha \\
{[\mathrm{mm}]}\end{array}$} & \multirow{2}{*}{$\begin{array}{c}b \\
{\left[{ }^{\circ}\right]}\end{array}$} & \multicolumn{7}{|c|}{ Thickness [mm] } \\
\hline & & & & 0.5 & 1 & 2 & 3 & 4 & 5 & 6 \\
\hline 11.10 & 10 & 30 & 15 & . & . & . & . & & & \\
\hline 18.30 & 16 & 30 & 25 & . & . & . & . & . & & \\
\hline 23.06 & 20 & 30 & 35 & . & . & . & . & . & . & . \\
\hline 34.21 & 30 & 40 & 50 & . & . & . & . & . & . & . \\
\hline 43.73 & 40 & 80 & 50 & . & . & . & . & . & . & . \\
\hline 53.73 & 50 & 80 & 35 & . & . & . & . & . & . & . \\
\hline
\end{tabular}

\section{Results}

\subsection{Problem (a)-Material Characterization}

In this section it will be presented, with detail, the results obtained for problem (a) in order to evaluate the influence of Swift parameter prediction error directly on a stress-strain curve. In this context, Figure 17 illustrates in a graphical format the 91 combinations of $K-n$ used for the neural network development. This diagram shows not only the expected target (circle marker) but also the ANN output (star marker). The train data set (light color) and the validation/test data set (dark color) are all represented. These results support the performance analysis presented in Section 3.1 since, in general, the developed ANN can predict with accuracy the Swift parameters for the majority of the total cases. However, for some combinations, a substantial disagreement between output and target value is evident, especially for cases that belong to the validation and testing data set. Table 6 summarizes the differences between target-output values, for different cases $C_{1}$ to $C_{4}$, also identified in Figure 17, in terms of relative error for both Swift parameters. For case $C_{1}$, the relative errors are quite low (less than $0.5 \%$ ) as expected, since this combination belongs to the train data set. On the contrary for cases belonging to validation/test data set $\left(C_{2}, C_{3}\right.$, $\mathrm{C}_{4}$ ) the errors are systematically higher, however always bellow $5 \%$, except for one case (C4) which is bellow $9 \%$. The higher error (C4) occur in 1 out of 91 cases, and therefore it can be considered an outlier for the test/validation data set.

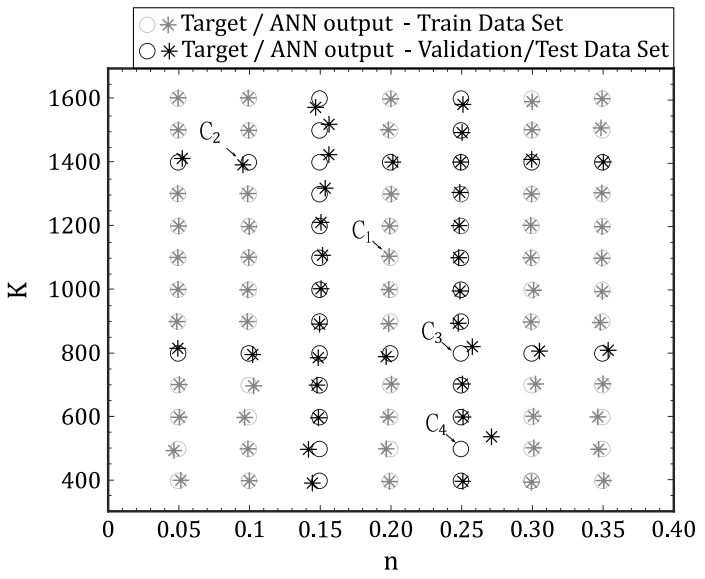

Figure 17. Graphical comparison between targets and ANN output values for the $91 \mathrm{~K}-n$ combinations.

In order to evaluate the influence of the Swift parameter error on a true stress-strain curve, Figure 18a compares the difference for cases $C_{1}$ to $C_{4}$ when considering the target Swift parameters (solid line) and the parameters obtained using the developed ANN (dotted line). From the graph it can be noted that case $C_{4}$ presents the largest gap between the two $\sigma-\varepsilon$ curves especially for higher true strain values. However, as seen in Figure $18 \mathrm{~b}$, the true stress error, represented by the absolute difference $\left(\left|\sigma_{A N N}-\sigma_{\text {target }}\right|\right)$ for each value of true strain, is less than $15 \mathrm{MPa}$, which in this context can be considered completely acceptable. 


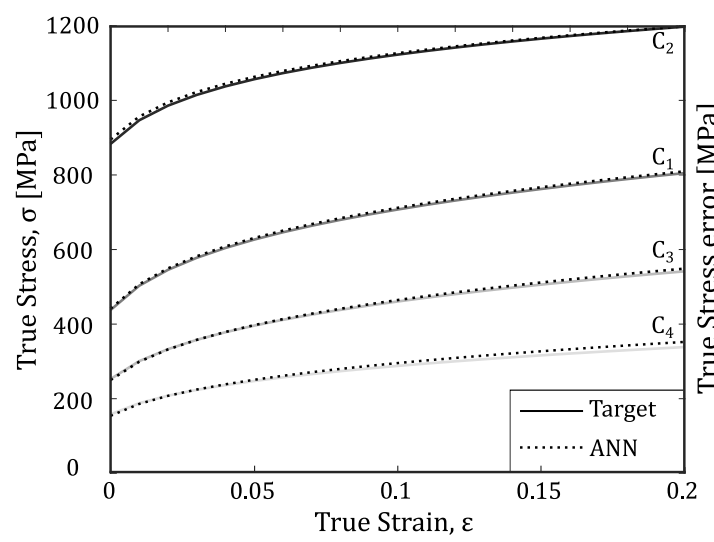

(a)

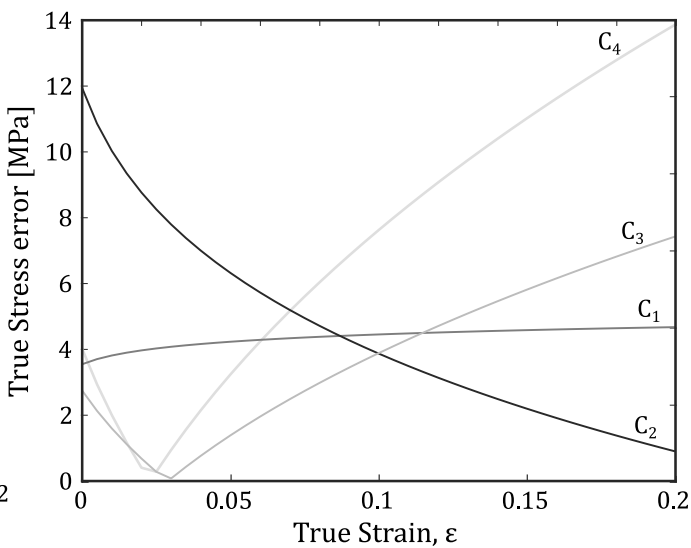

(b)

Figure 18. True stress-strain curves (a) for cases $C_{1}$ to $C_{4}$ considering the Swift parameters obtained using ANN and its comparison with the expected target results; (b) corresponding true stress error $\left(\left|\sigma_{\text {Target }}-\sigma_{A N N}\right|\right)$ for each case and true strain values between [0, 0.2].

Table 6. Relative error [\%] between the target reference and the ANN output values of four different cases $\left(C_{1}\right.$ to $\left.C_{4}\right)$ and considering two Swift parameters ( $K$ and $n$ ).

\begin{tabular}{ccccccc}
\hline & $\boldsymbol{K}_{\text {Target }}$ & $\boldsymbol{K}_{\text {ANN }}$ & $\left|\boldsymbol{K}_{\text {Relative Error }}\right|$ & $\boldsymbol{n}_{\text {Target }}$ & $\boldsymbol{n}_{\text {ANN }}$ & $\left|\boldsymbol{n}_{\text {Relative Error }}\right|$ \\
\hline Case 1-C & 1100 & 1105 & $0.5 \%$ & 0.200 & 0.199 & $0.5 \%$ \\
Case 2-C & 1400 & 1392 & $0.6 \%$ & 0.100 & 0.096 & $4.0 \%$ \\
Case 3-C $-C_{3}$ & 800 & 821 & $2.6 \%$ & 0.250 & 0.258 & $3.2 \%$ \\
Case 4-C & 500 & 538 & $7.6 \%$ & 0.250 & 0.272 & $8.8 \%$ \\
\hline
\end{tabular}

\section{Complementary Test}

In order to confirm the results prediction, complementary tests were performed. For that purpose, an additional database was created, using FEA, considering Swift parameters that were not used in the development of the ANN. These new target parameters ( $K_{\text {target }}$ and $\left.n_{\text {target }}\right)$ are summarized in Table 7 for six different extra tests. Additionally, the numerical punch force-displacement curves are represented in Figure 19a for each extra case. In this point it is important to note that the extra cases two and five have similar $F_{p}-y_{p}$ curves, and this proximity is especially evident in the elastic-plastic transition zone. However, the Swift parameters are completely distinct. Regarding the ANN prediction for these extra cases, the Swift parameters obtained using the developed neural network $\left(K_{A N N}\right.$ and $\left.n_{A N N}\right)$ are in closer agreement with the targets, with relative errors below $2.5 \%$ for $\mathrm{ExT}_{2-6}$ and $5.8 \%$ for $\mathrm{ExT}_{1}$. Figure $19 \mathrm{~b}$ represents the resulting hardening Swift curves (Equation (1)) for these considered extra cases with the parameters predicted using ANN $\left(K_{A N N}, n_{A N N}\right)$ and the corresponding reference values $\left(K_{\text {target }}, n_{\text {target }}\right)$. As previously observed, the true stress-strain curves (Swift) for both cases are in a good agreement for strain values between 0-0.2. Among these new cases, the ExT 2 and $\mathrm{ExT}_{5}$ are of particular interest as, although having closer three-point bending test curves, the respective stress-strain curves are quite different. Observing the ANN performance in these two cases, Figure 19b, it can be verified that the ANN performs equally well. Therefore, it can be concluded that the five point selection, that represents the information from the bending test curves given to the ANN, it was usefully used by the trained ANN. 


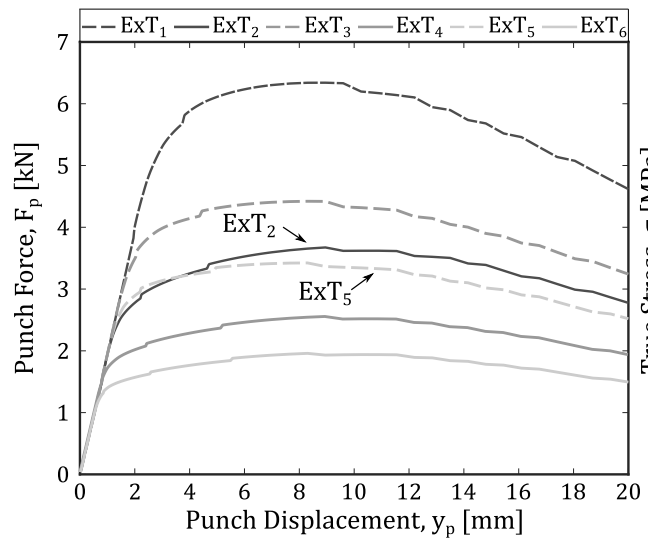

(a)

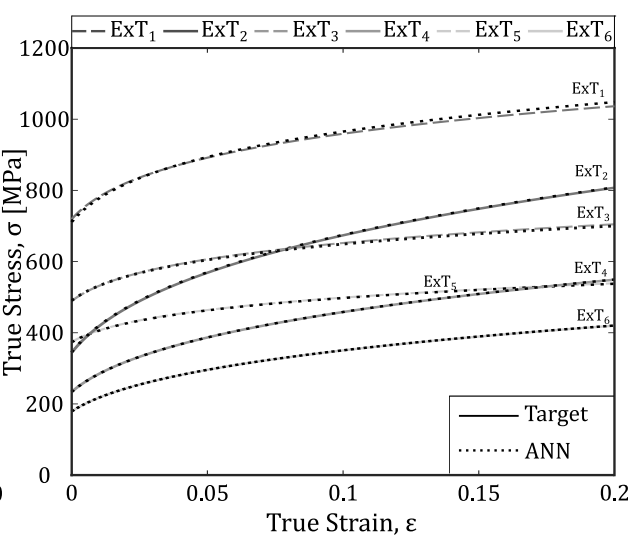

(b)

Figure 19. Three point bending test (a) punch force-displacement curves $\left(F_{p}-y_{p}\right)$ obtained by finite element analysis for extra cases $\operatorname{ExT}_{1}$ to $\operatorname{ExT}_{6}$, and $(\mathbf{b})$ the corresponding true stress-strain curves $(\sigma-\varepsilon)$.

Table 7. Relative Error [\%] between the target reference and the ANN output values for six different extra cases $\left(\operatorname{ExT}_{1}\right.$ to $\left.\operatorname{ExT}_{6}\right)$ and considering two Swift parameters ( $K$ and $\left.n\right)$.

\begin{tabular}{ccccccc}
\hline & $\boldsymbol{K}_{\text {Target }}$ & $\boldsymbol{K}_{\text {ANN }}$ & $\left|\boldsymbol{K}_{\text {Relative Error }}\right|$ & $\boldsymbol{n}_{\text {Target }}$ & $\boldsymbol{n}_{\text {ANN }}$ & $\left|\boldsymbol{n}_{\text {Relative Error }}\right|$ \\
\hline $\mathrm{ExT}_{1}$ & 1250 & 1278 & $2.3 \%$ & 0.120 & 0.127 & $5.8 \%$ \\
$\mathrm{ExT}_{2}$ & 1250 & 1250 & $\sim 0.0 \%$ & 0.280 & 0.279 & $0.4 \%$ \\
$\mathrm{ExT}_{3}$ & 850 & 840 & $1.2 \%$ & 0.120 & 0.117 & $2.5 \%$ \\
$\mathrm{ExT}_{4}$ & 850 & 851 & $0.1 \%$ & 0.280 & 0.280 & $\sim 0.0 \%$ \\
$\mathrm{ExT}_{5}$ & 650 & 648 & $0.3 \%$ & 0.120 & 0.120 & $\sim 0.0 \%$ \\
$\mathrm{ExT}_{6}$ & 650 & 651 & $0.2 \%$ & 0.280 & 0.280 & $\sim 0.0 \%$ \\
\hline
\end{tabular}

\subsection{Problem (b)-Air Bending: Forming and Springback Prediction}

Turning now to problem (b), in this section it will be presented the results obtained by the multitask ANN developed in Section 3.2, using the DD1 division set (MT-ANN, DD1). In this context, Figure 20a,b details, respectively, the punch displacement $\left(y_{p}\right)$ and the springback angle $\left(\Delta \alpha_{S B}\right)$ curves as a function of required bending angle $(\alpha)$, for the $37 \mathrm{~V} / t$ combinations. This representation illustrates the overall capability of the developed ANN to model, in the same structure, two different, although related, functions ( $y_{p}$ and $\left.\Delta \alpha_{S B}\right)$, and in a significant range of input parameter values ( $V, t$, bending angle). It can also be observed that in the prediction of the springback angle, higher oscillations occur in relation to the reference curves.

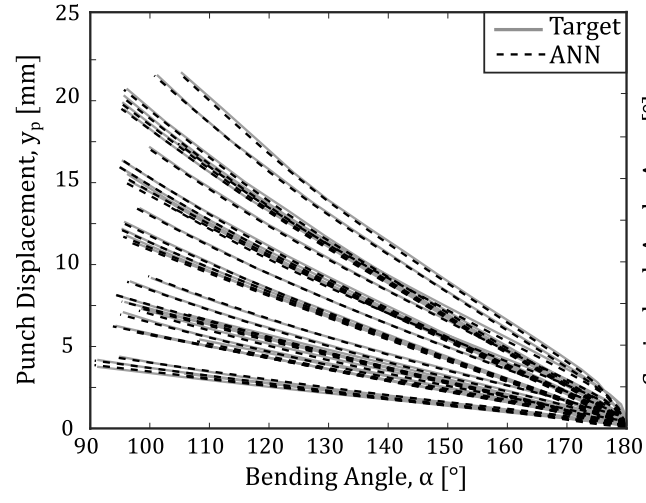

(a)

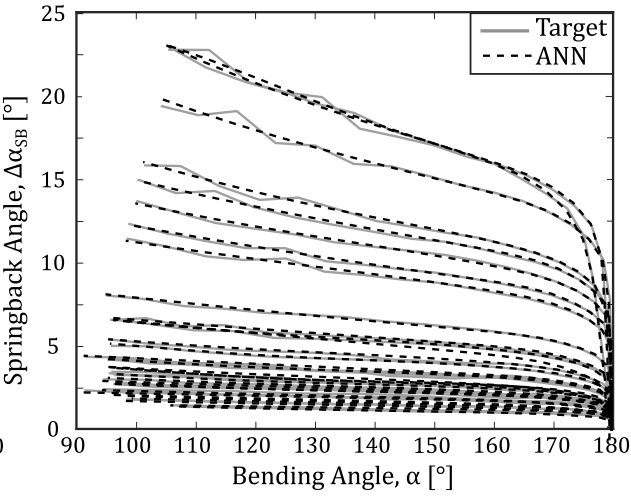

(b)

Figure 20. (a) Punch displacement $\left(y_{p}\right)$ graph and (b) springback angle $\left(\Delta \alpha_{S B}\right)$ graph as a function of required bending angle $(\alpha)$ for the total $V / t$ combinations used in problem (b). 
In order to evaluate the results of this problem in more detail, the three cases (A, B and C), presented in Section 2.1.2 (Figures 4-6), will be studied in this analysis. As already mentioned, these three cases correspond to different bending conditions: case $\mathrm{A}(V / t=43.7)$ is characterized by an excessive springback angle, case $C(V / t=8.7)$ is characterized by indentation, and finally case B $(V / t=4.6)$ where none of these phenomena occur and the bending conditions are considered appropriate, in closer agreement with analytical models and industry guidelines. Additionally, it can be noted that cases $\mathrm{A}$ and $\mathrm{B}$ belong to the test and validation data set, while case $\mathrm{C}$ belongs to the training data set, following the proposed data sets division (DD1), as represented in Figure 15a. It can be observed (Figure 21) that the ANN performs equally well in the three cases, which means it can provide a solution to a wide extension of the bending angles, that can be obtained with the same set of tools, in addition to the industry guidelines.

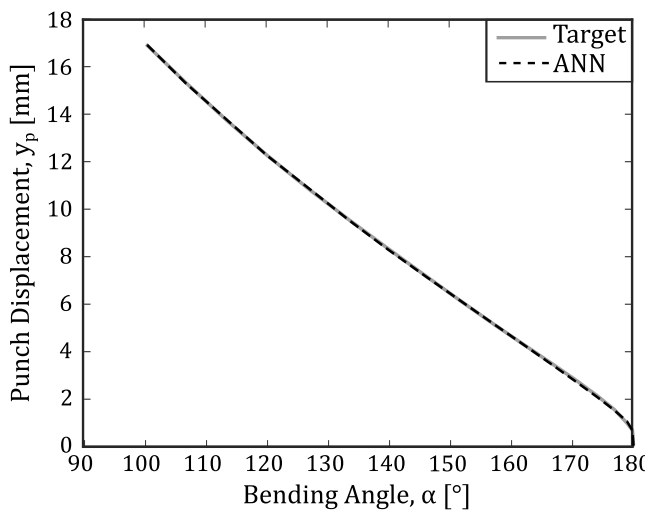

(a) Case A-Punch Displacement

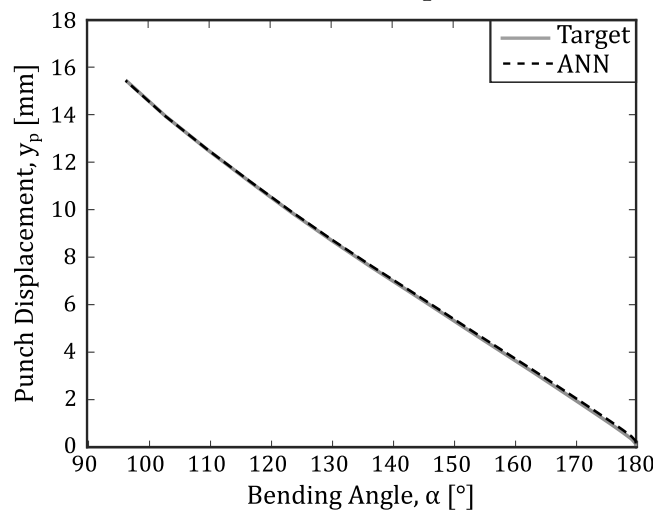

(c) Case B-Punch Displacement

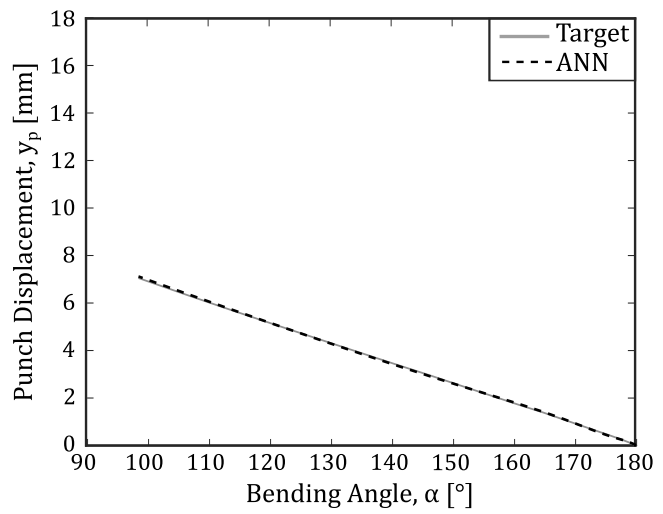

(e) Case C-Punch Displacement

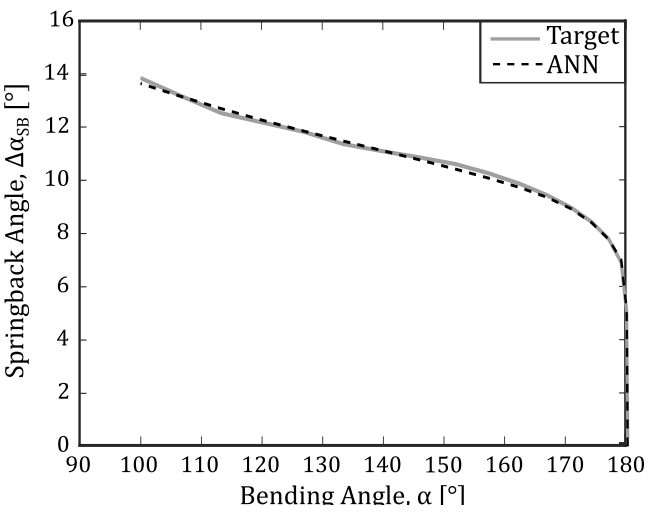

(b) Case A-Springback Angle

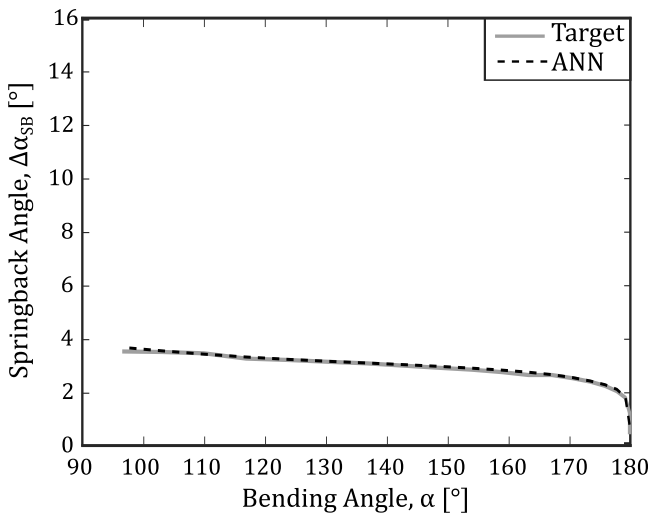

(d) Case B-Springback Angle

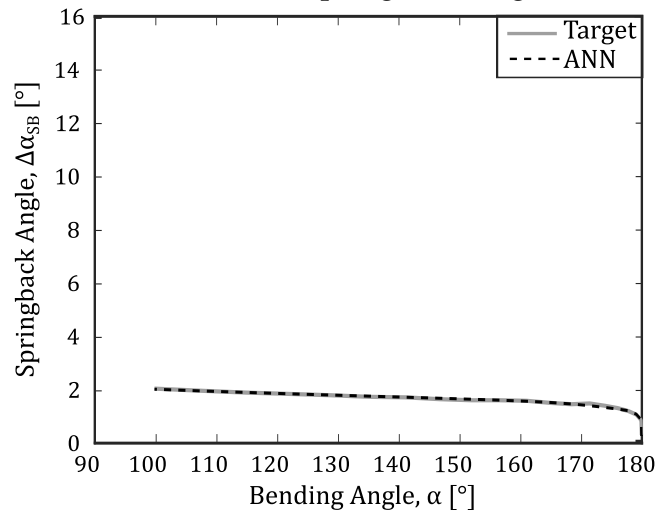

(f) Case C-Springback Angle

Figure 21. Punch displacement $\left(y_{p}\right)$ graphs and springback angle $\left(\Delta \alpha_{S B}\right)$ graphs as a function of required bending angle $(\alpha)$ for cases $\mathrm{A}, \mathrm{B}, \mathrm{C}$. 
In order to have a closer look at the capability of ANN to model the punch displacement, Figure 22 includes both the $y_{p}$ and error graphs in case B, which favors the analytical or geometrical based solutions. It contains the $y_{p}$ reference curves obtained from simulation, after $\left(y \operatorname{Sim}_{A S B}\right)$ and before $\left(y \operatorname{Sim}_{B S B}\right)$ springback, the analytical solution $\left(y_{J B P}\right)$ and the ANN solution $\left(y_{A N N}\right)$. Although the $y_{p}$ curves seem to have a similar behavior, the error curves clearly differentiate the analytical solution when compared to the reference simulation curves, before springback and even more when springback is taken into account. Comparatively the ANN solution presents a lower error relative to reference simulation curve after springback, demonstrating that it provides an adequate solution even when springback is considered.

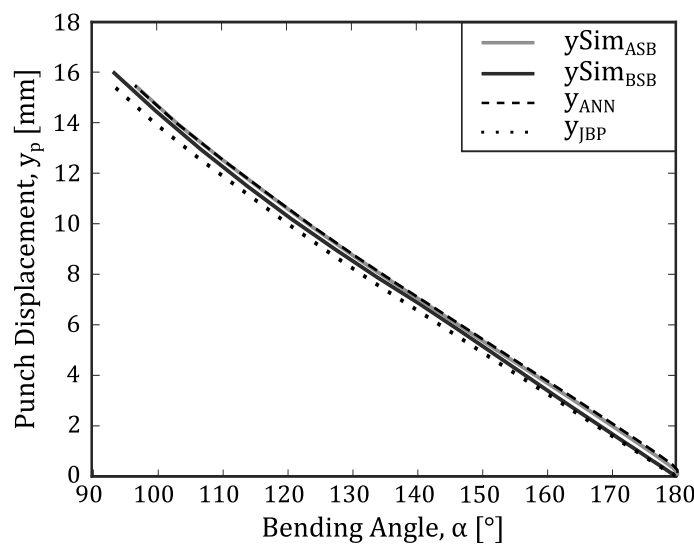

(a)

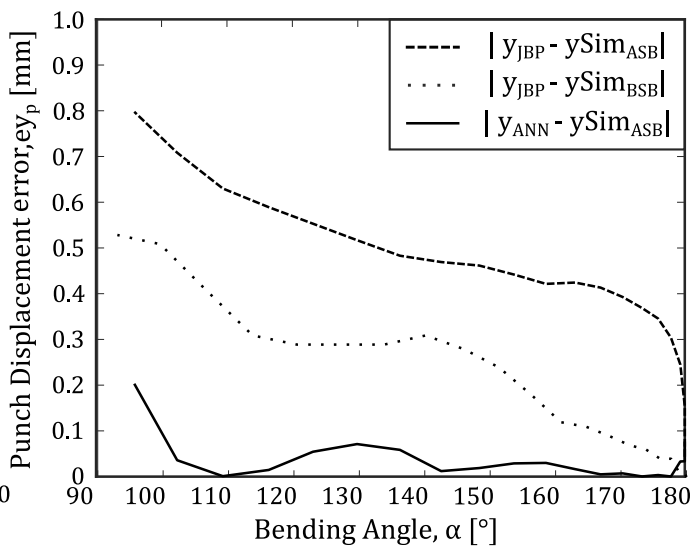

(b)

Figure 22. Punch displacement errors $\left(e y_{p}\right)$, for case B, as a function of required bending angle $(\alpha)$ considering ANN output values and JBP analytical results.

In order to evaluate the error of the ANN solution when predicting the springback angle $\left(\Delta \alpha_{S B}\right)$, Figure 23 represents, for the previously described three cases $(\mathrm{A}, \mathrm{B}, \mathrm{C})$ the evolution of springback angle $\left(\Delta \alpha_{S B}\right)$ and the respective error curves relative to the simulation reference springback angle. In the overall, evolution of $\left(\Delta \alpha_{S B}\right)$ angles follow a similar behavior to the reference curves and the errors are clearly higher and more irregular in case A, than B and C. This indicates higher difficulty in this area of the tools usage $(V / t>10)$. However, taking into account the objective of having an indicator of the magnitude of the springback angle, rather than a precise value for the user, the ANN solution can be considered to fulfill its purpose adequately.

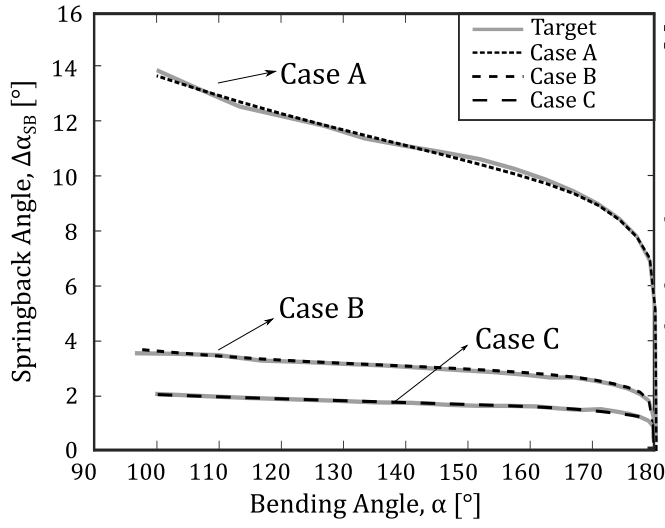

(a)

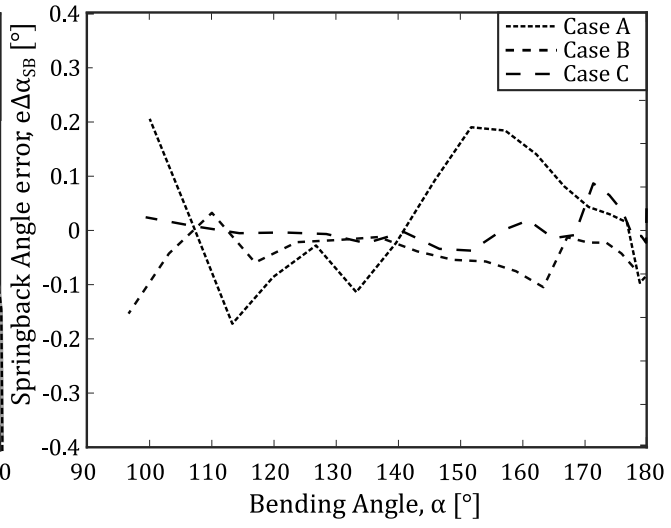

(b)

Figure 23. Sprinback analysis for cases A, B, C: (a) springback angle $\left(\Delta \alpha_{S B}\right)$ and the corresponding expected value (Target) as a function of required bending angle $(\alpha) ;(\mathbf{b})$ springback angle error $\left(e \Delta \alpha_{S B}\right)$ for each case as a function of required bending angle $(\alpha)$. 


\section{Conclusions}

In this work, the use of machine learning algorithms was explored in the form of artificial neural networks to model different problems associated with sheet metal processing and material characterization. The ANN methods have the advantage of an efficient modeling of the complexity and nonlinearities associated with these problems. However, it must be considered that they do not provide by themselves an explicative solution for the problems nor a confidence level of the results obtained. Therefore, its usage must be carefully considered and other ML tools and methods could provide a complementary solution to overcome some of these limitations. First, it was intended to use the results of a simple and standard test (three-point bending) to perform the mechanical characterization of a metallic sheet material and finding the corresponding parameters for the Swift hardening curve. Second, in a different but related problem, it was intended to model the sheet metal press brake, air-bending process, to predict the required punch displacement corresponding to the desired bending angle, after removing the tools (i.e., after springback). In both cases, simulation results obtained with FEA models were used. The obtained results show that ANN can be a valuable tool to model these problems.

In the first problem, mechanical characterization with three-point bending, the results show a good agreement with the simulation and reference models, being able to closely predict the material $K$ and $n$ parameters in the ranges 400 to 1600 , and 0.05 to 0.35 respectively, and characterizing adequately the strain-stress curves in the range of interest, i.e., up to 0.2 strain values. In the second problem, press-brake bending, it can be concluded that a single structure ANN was efficient in predicting simultaneously the required punching displacement and the springback angle. It was also proved beneficially to include a second learning task to better predict the punch displacement.

In spite of having more than two hidden layers, the ANN developed can be considered within a simpler shallow ANN classification, rather than included in deep learning ANN structures. Shallow ANN has the advantage of being faster to train and requiring less data. However, when expanding the solution to include other materials, tools or process parameters it can be expected that a deep learning structure will be beneficial. One envisaged future work will be to use convolution neural networks (CNN) in a deep learning structure. This approach allows for the use of more information about a problem to be included in the Input layer, without having the corresponding increase of the ANN size as in fully connected feedforward structures. Regarding the first problem, it may be explored whether the complete curve would provide better generalization. As for the second problem, it is intended to include the material force-displacement behavior in the learning tasks, to evaluate at what level the precision and generalization ability of the ANN can be guided using this information. In general, it is intended to expand the solutions for these problems by comparing ANN solutions with other methods in an attempt to include more materials and associated increased data sets.

Author Contributions: Data curation, R.L.A.; Investigation, D.J.C. and S.S.M.; Methodology, D.J.C., M.R.B. and A.D.S.; Software, D.J.C., A.D.S. and R.L.A.; Supervision, M.R.B.; Validation, A.D.S.; Visualization, D.J.C.; Writing—original draft, D.J.C.; Writing—review \& editing, M.R.B. and A.D.S. All authors have read and agreed to the published version of the manuscript.

Funding: This research was funded by Project POCI-01-0145-FEDER-031243 - RDFORMINGRobust Design of Sheet Metal Forming Processes to Reduce Productivity Losses, cofinanced by Programa Operacional Competitividade e Internacionalização (Compete2020), through Fundo Europeu de Desenvolvimento Regional (FEDER) and by Fundação para a Ciência e Tecnologia through its component of the state budget. The fourth author is also grateful to the FCT for the Doctoral grant SFRH/BD/146083/2019 under the program POCH, cofinanced by the European Social Fund (FSE) and Portuguese National Funds from MCTES.

Institutional Review Board Statement: Not applicable.

Informed Consent Statement: Not applicable. 


\section{Data Availability Statement: Not applicable.}

Acknowledgments: The authors highlight their appreciation and gratitude for the availability and fruitful discussions with our colleague and industry expert J. Bessa Pacheco.

Conflicts of Interest: The authors declare no conflict of interest.

\section{References}

1. Zheng, K.; Politis, D.J.; Wang, L.; Lin, J. A review on forming techniques for manufacturing lightweight complex-Shaped aluminium panel components. Int. J. Lightweight Mater. Manuf. 2018, 1, 55-80. [CrossRef]

2. Pacheco, J.B.; Santos, A.D. A Study on the Nose Radius Influence in Press Brake Bending Operations by Finite Element Analysis. Key Eng. Mater. 2013, 554-557, 1432-1442. [CrossRef]

3. Miranda, S.S.; Barbosa, M.R.; Santos, A.D.; Pacheco, J.B.; Amaral, R.L. Forming and springback prediction in press brake air bending combining finite element analysis and neural networks. J. Strain Anal. Eng. Des. 2018, 53, 584-601. [CrossRef]

4. Rodrigues, J.; Martins, P. Tecnologia Mecanica (Mechanical Technology); Escolar Editora: Lisboa, Portugal, 2005; Volume I.

5. de Vin, L. Computer Aided Process Planning for the Bending of Sheet Metal Components. Ph.D. Thesis, University of Twente, Enschede, The Netherlands, 1994.

6. Vin, L.D.; Streppel, A.H.; Singh, U.; Kals, H. A process model for air bending. J. Mater. Process. Technol. 1996, 57, 48-54. [CrossRef]

7. De Vin, L. Curvature prediction in air bending of metal sheet. J. Mater. Process. Technol. 2000, 100, 257-261. [CrossRef]

8. Pacheco, J.B.; Santos, A.D. Numerical Simulation on thevalidation of a press brake design criteria to minimizeangle deviations. In Proceedings of the CMNE 2011—Congresso de Métodos Numéricos em Engenharia, Conference Proceedings, Coimbra, Portugal, 14-17 June 2011.

9. Wang, C.; Kinzel, G.; Altan, T. Mathematical modeling of plane-strain bending of sheet and plate. J. Mater. Process. Technol. 1993, 39, 279-304. [CrossRef]

10. Tekkaya, A. State-of-the-art of simulation of sheet metal forming. J. Mater. Process. Technol. 2000, 103, 14-22. [CrossRef]

11. Tisza, M. Numerical modelling and simulation in sheet metal forming. J. Mater. Process. Technol. 2004, 151, 58-62. [CrossRef]

12. Vorkov, V.; Aerens, R.; Vandepitte, D.; Duflou, J.R. Springback Prediction of High-strength Steels in Large Radius Air Bending Using Finite Element Modeling Approach. Procedia Eng. 2014, 81, 1005-1010. [CrossRef]

13. Lingbeek, R.; Huétink, J.; Ohnimus, S.; Petzoldt, M.; Weiher, J. Thedevelopment of a finite elements based springback compensation toolfor sheet metal products. J. Mater. Process. Technol. 2005, 169, 115-125. [CrossRef]

14. Li, Y.; Rong, Q.; Shi, Z.; Sun, X.; Meng, L.; Lin, J. An accelerated springback compensation method for creep age forming. Int. J. Adv. Manuf. Technol. 2018, 102, 121-134. [CrossRef]

15. Ingarao, G.; Lorenzo, R.D. Design of Complex Sheet Metal Forming Processes: A New Computer Aided Progressive Approach. Int. J. Mater. Form. 2010, 3, 21-24. [CrossRef]

16. Katsikopoulos, K.V.; Durbach, I.N.; Stewart, T.J. When should we use simple decision models? A synthesis of various research strands. Omega 2018, 81, 17-25. [CrossRef]

17. Bock, F.E.; Aydin, R.C.; Cyron, C.J.; Huber, N.; Kalidindi, S.R.; Klusemann, B. A Review of the Application of Machine Learning and Data Mining Approaches in Continuum Materials Mechanics. Front. Mater. 2019, 6, 110. [CrossRef]

18. Cao, J.; Brinksmeier, E.; Fu, M.; Gao, R.X.; Liang, B.; Merklein, M.; Schmidt, M.; Yanagimoto, J. Manufacturing of advanced smart tooling for metal forming. CIRP Ann. 2019, 68, 605-628. [CrossRef]

19. Jaremenko, C.; Ravikumar, N.; Affronti, E.; Merklein, M.; Maier, A. Determination of Forming Limits in Sheet Metal Forming Using Deep Learning. Materials 2019, 12, 1051. [CrossRef]

20. Liu, S.; Shi, Z.; Lin, J.; Li, Z. Reinforcement learning in free-form stamping of sheet-metals. Procedia Manuf. 2020, 50, 444-449. [CrossRef]

21. Liu, X.; Du, Y.; Lu, X.; Zhao, S. Springback Prediction and Forming Accuracy Control of Micro W-bending Using Support Vector Machine. In Proceedings of the 2019 6th International Conference on Frontiers of Industrial Engineering (ICFIE), London, UK, 10-12 September 2019; pp. 23-27.

22. Dib, M.A.; Oliveira, N.J.; Marques, A.E.; Oliveira, M.C.; Fernandes, J.V.; Ribeiro, B.M.; Prates, P.A. Single and ensemble classifiers for defect prediction in sheet metal forming under variability. Neural Comput. Appl. 2019, 32, 12335-12349. [CrossRef]

23. Pathak, K.; Panthi, S.; Ramakrishnan, N. Application of Neural Network in Sheet Metal Bending Process. Def. Sci. J. 2005, 55, 125-131. [CrossRef]

24. Forcellese, A.; Gabrielli, F.; Ruffini, R. Effect of the training set size on springback control by neural network in an air bending process. J. Mater. Process. Technol. 1998, 80-81, 493-500. [CrossRef]

25. Spathopoulos, S.C.; Stavroulakis, G.E. Springback Prediction in Sheet Metal Forming, Based on Finite Element Analysis and Artificial Neural Network Approach. Appl. Mech. 2020, 1, 97-110. [CrossRef]

26. Trzepieciński, T.; Lemu, H.G. Improving Prediction of Springback in Sheet Metal Forming Using Multilayer Perceptron-Based Genetic Algorithm. Materials 2020, 13, 3129. [CrossRef] [PubMed]

27. Baseri, H.; Bakhshi-Jooybari, M.; Rahmani, B. Modeling of spring-back in V-die bending process by using fuzzy learning back-propagation algorithm. Expert Syst. Appl. 2011, 38, 8894-8900. [CrossRef] 
28. Inamdar, M.; Date, P.; Desai, U. Studies on the prediction of springback in air vee bending of metallic sheets using an artificial neural network. J. Mater. Process. Technol. 2000, 108, 45-54. [CrossRef]

29. Viswanathan, V.; Kinsey, B.; Cao, J. Experimental Implementation of Neural Network Springback Control for Sheet Metal Forming. J. Eng. Mater. Technol. 2003, 125, 141-147. [CrossRef]

30. Fu, Z.; Mo, J.; Chen, L.; Chen, W. Using genetic algorithm-back propagation neural network prediction and finite-element model simulation to optimize the process of multiple-step incremental air-bending forming of sheet metal. Mater. Des. 2010, 31, 267-277. [CrossRef]

31. Narayanasamy, R.; Padmanabhan, P. Comparison of regression and artificial neural network model for the prediction of springback during air bending process of interstitial free steel sheet. J. Intell. Manuf. 2010, 23, 357-364. [CrossRef]

32. Özgü Şenol.; Esat, V.; Darendeliler, H. Springback Analysis in Air Bending Process through Experiment based Artificial Neural Networks. Procedia Eng. 2014, 81, 999-1004.

33. Guo, Z.; Tang, W. Bending Angle Prediction Model Based on BPNN-Spline in Air Bending Springback Process. Math. Probl. Eng. 2017, 2017, 1-11. [CrossRef]

34. Liu, S.; Xia, Y.; Shi, Z.; Yu, H.; Li, Z.; Lin, J. Deep Learning in Sheet Metal Bending with a Novel Theory-Guided Deep Neural Network. IEEE/CAA J. Autom. Sin. 2021, 8, 565-581. [CrossRef]

35. Eggertsen, P.A.; Mattiasson, K. An efficient inverse approach for material hardening parameter identification from a three-point bending test. Eng. Comput. 2009, 26, 159-170. [CrossRef]

36. Gorji, M.B.; Mozaffar, M.; Heidenreich, J.N.; Cao, J.; Mohr, D. On the potential of recurrent neural networks for modeling path dependent plasticity. J. Mech. Phys. Solids 2020, 143, 103972. [CrossRef]

37. Jenab, A.; Sari Sarraf, I.; Green, D.E.; Rahmaan, T.; Worswick, M.J. The Use of genetic algorithm and neural network to predict rate-dependent tensile flow behaviour of AA5182-O sheets. Mater. Des. 2016, 94, 262-273. [CrossRef]

38. Lin, Y.; Zhang, J.; Zhong, J. Application of neural networks to predict the elevated temperature flow behavior of a low alloy steel. Comput. Mater. Sci. 2008, 43, 752-758. [CrossRef]

39. Zhang, A.; Mohr, D. Using neural networks to represent von Mises plasticity with isotropic hardening. Int. J. Plast. 2020, 132, 102732. [CrossRef]

40. Gorji, M.B.; Mohr, D. Towards neural network models for describing the large deformation behavior of sheet metal. IOP Conf. Ser. Mater. Sci. Eng. 2019, 651, 012102. [CrossRef]

41. Li, X.; Roth, C.C.; Mohr, D. Machine-learning based temperature- and rate-dependent plasticity model: Application to analysis of fracture experiments on DP steel. Int. J. Plast. 2019, 118, 320-344. [CrossRef]

42. Garcia-Romeu, M.; Ciurana, J.; Ferrer, I. Springback determination of sheet metals in an air bending process based on an experimental work. J. Mater. Process. Technol. 2007, 191, 174-177. [CrossRef]

43. Raabe, D.; Roters, F.; Barlat, F.; Chen, L.Q. Continuum Scale Simulation of Engineering Materials: Fundamentals, Microstructures, Process Applications; Wiley-VCH: Weinheim, Germany, 2004.

44. Standard Test Methods For Bend Testing Of Material For Ductility; ASTM International: West Conshohocken, PA, USA, 2014.

45. Naseem, S.; Perdahcıoğlu, E.S.; Geijselaers, H.J.M.; van den Boogaard, A.H. A New in-Plane Bending Test to Determine Flow Curves for Materials with Low Uniform Elongation. Exp. Mech. 2020, 60, 1225-1238. [CrossRef]

46. Kim, Y.J.; Lee, C.H.; Kim, J.H.; Lim, J.H. Numerical modeling of shape memory alloy plates considering tension/compression asymmetry and its verification under pure bending. Int. J. Solids Struct. 2018, 136-137, 77-88. [CrossRef]

47. Badr, O.M.; Rolfe, B.; Zhang, P.; Weiss, M. Applying a new constitutive model to analyse the springback behaviour of titanium in bending and roll forming. Int. J. Mech. Sci. 2017, 128-129, 389-400. [CrossRef]

48. Capilla, G.; Hamasaki, H.; Yoshida, F. Determination of uniaxial large-strain workhardening of high-strength steel sheets from in-plane stretch-bending testing. J. Mater. Process. Technol. 2017, 243, 152-169. [CrossRef]

49. Nádai, Á.; Wahl, A.M.; Bingham, E.C. Plasticity, A Mechanics of the Plastic State of Matter. J. Rheol. 1931, 2, 455-456. [CrossRef]

50. Rumelhart, D.E.; Hinton, G.E.; Williams, R.J. Learning representations by back-propagating errors. Nature 1986, 323, 533-536. [CrossRef]

51. Hertz, J.; Krogh, A.; Palmer, R.G. Introduction to the Theory of Neural Computation; CRC Press: Boca Raton, FL, USA, 2018.

52. Goodfellow, I.; Bengio, Y.; Courville, A. Deep Learning; MIT Press: Cambridge, MA, USA, 2016.

53. Ferreira, B. Integração de Metodologias de Análise do Processo de Quinagem. Master's Thesis, Faculdade de Engenharia da Universidade do Porto, Porto, Portugal, 2015.

54. MATLAB. Version 9.10.0 (R2021a); The MathWorks Inc.: Natick, MA, USA, 2010.

55. MATLAB Deep Learning Toolbox ${ }^{\mathrm{TM}}$ User's Guide: PDF Documentation for Release R2021a; The MathWorks Inc.: Natick, MA, USA, 2021. 